\title{
Demand-side financing for maternal and newborn health: what do we know about factors that affect implementation of cash transfers and voucher programmes?
}

\author{
Benjamin M. Hunter ${ }^{*}$ and Susan F. Murray
}

\begin{abstract}
Background: Demand-side financing (DSF) interventions, including cash transfers and vouchers, have been introduced to promote maternal and newborn health in a range of low- and middle-income countries. These interventions vary in design but have typically been used to increase health service utilisation by offsetting some financial costs for users, or increasing household income and incentivising 'healthy behaviours'. This article documents experiences and implementation factors associated with use of DSF in maternal and newborn health.
\end{abstract}

Methods: A secondary analysis (using an adapted Supporting the Use of Research Evidence framework - SURE) was performed on studies that had previously been identified in a systematic review of evidence on DSF interventions in maternal and newborn health.

Results: The article draws on findings from 49 quantitative and 49 qualitative studies. The studies give insights on difficulties with exclusion of migrants, young and multiparous women, with demands for informal fees at facilities, and with challenges maintaining quality of care under increasing demand. Schemes experienced difficulties if communities faced long distances to reach participating facilities and poor access to transport, and where there was inadequate health infrastructure and human resources, shortages of medicines and problems with corruption. Studies that documented improved care-seeking indicated the importance of adequate programme scope (in terms of programme eligibility, size and timing of payments and voucher entitlements) to address the issue of concern, concurrent investments in supply-side capacity to sustain and/or improve quality of care, and awareness generation using community-based workers, leaders and women's groups.

Conclusions: Evaluations spanning more than 15 years of implementation of DSF programmes reveal a complex picture of experiences that reflect the importance of financial and other social, geographical and health systems factors as barriers to accessing care. Careful design of DSF programmes as part of broader maternal and newborn health initiatives would need to take into account these barriers, the behaviours of staff and the quality of care in health facilities. Research is still needed on the policy context for DSF schemes in order to understand how they become sustainable and where they fit, or do not fit, with plans to achieve equitable universal health coverage.

Keywords: Demand-side financing, Vouchers, Cash transfers, Maternal health, Newborn health, Implementation

\footnotetext{
* Correspondence: benjamin.hunter@kcl.ac.uk

King's College London, Department of International Development, The

Strand, London WC2R 2LS, UK
} 


\section{Background}

Women and their families can face multiple barriers to accessing maternity care services, and financial barriers are a well-documented concern $[1,2]$. In many countries there are demands for out-of-pocket formal fees and informal payments for care services or supplies such as medicines, sutures, gloves and diagnostic tests [3, 4]. There are the practical and financial difficulties of travel to health centres and the opportunity costs of being away from home or from work, or from dependents. For poor families, any such costs can cause severe financial hardship [5], and may result in delays or avoidance of care-seeking that increase health risks for mothers and newborns and further escalate costs. One approach to ameliorate these effects is the use of 'demand-side' financing (DSF) interventions that are designed to promote health by providing cash or vouchers to users to offset some of the financial costs of using or getting to maternity care services, or to increase household income and incentivise 'healthy behaviours'.

Within this overarching definition there are five types of DSF that have been used in the health sector and there are important differences in their intended mechanism of action [6, 7]. Conditional cash transfers, which have been widely used in Latin America, aim to increase utilisation of maternity care services by making regular payments to households linked to 'conditionalities' including attendance at community meetings and uptake of government health services. These are primarily focused on child health and development but some schemes include maternity care uptake. Unconditional cash transfers are similar regular payments but, in the absence of specific conditionalities for service utilisation, have the more general aim of alleviating the effect of poverty on a woman's health during pregnancy. Shortterm cash payments to offset costs are typically retrospective payments made at government health facilities to those who attend for care. Vouchers for maternity care services aim to reduce the cost of maternity care services and vouchers for 'merit' goods aim to reduce the cost of merit goods (such as food or insecticide-treated nets) that promote maternal health. Vouchers may be distributed by community-based workers or at health facilities, and voucher schemes may be designed to incorporate services in the private sector as well as government facilities.

There have been seven systematic reviews of evidence on the impact of DSF mechanisms on maternal health during the period 2007-2012 [7-13]. Two of the reviews examined the impact of cash transfers $[9,11]$, three the impact of vouchers $[8,12,13]$, and two the role of multiple types of DSF $[7,10]$. The systematic reviews reported on a rapidly growing body of evidence that DSF can lead to a short-term increase in uptake of maternity care services, but could offer little evidence on longer-term effects on service uptake or maternal and neonatal morbidity and mortality. A recently published systematic review has confirmed these findings [14].

This article has been commissioned by the World Health Organization's Department of Maternal, Newborn, Child and Adolescent Health as part of a series of articles on health promotion interventions. The series aims to document factors that affect programme implementation in order to support policy-makers and decisions on how best to improve access to skilled care during pregnancy, childbirth and after birth. This article focuses on factors that have been found to affect implementation of DSF programmes in maternal and newborn health and has three components: a review of stakeholder perspectives and experiences of DSF interventions; information on the barriers and facilitators to implementation of the interventions, and a discussion on how these relate to the improvements in care-seeking outcomes reported elsewhere and what this means for programmatic initiatives [14].

\section{Methods}

This article is a secondary analysis of studies identified in a systematic review that was conducted in $2012[6,7]$ and repeated in 2015 [14]. The systematic review used the Joanna Briggs Institute approach, which incorporates both quantitative and qualitative data into reviews and has been used to review evidence on a range of policy and healthcare systems topics [15]. The population of interest in the review was economically poor women who were pregnant or within 42 days of end of pregnancy, in the context of low- and middle-income (both lower- and upper-middle) countries as defined by the World Bank at the time the study was published. The intervention of interest was DSF as a mechanism to increase consumption of goods and services intended to impact positively on maternal and newborn health. Outcomes of interest in the systematic review related to the effectiveness of DSF programmes to promote uptake of maternity care services and maternal and newborn health, and wider impact on quality of care. In addition to questions of effectiveness, the 2012 review also analysed qualitative research relating to barriers and facilitators for effective and sustainable programme implementation.

The systematic searches for the review used 30 terms in 19 medical, health and social policy databases and seven databases of unpublished research, and aimed to retrieve quantitative and qualitative studies that were published between January 1990 and June 2015. Retrieved studies were examined using Joanna Briggs Institute tools for critical appraisal of quantitative and qualitative research that include questions on study methods and the presentation of findings [15]. The 
review team assigned an overall quality rating to individual studies using a three-point rating system (low-, mediumor high-quality), similar to that used to assess study bias in the Effective Public Health Practice Project (EPHPP) quality assessment tool. The rating assigned to each study was based on assessments of study methods and reporting using critical appraisal tools produced by the Joanna Briggs Institute. The assessments are described in detail in a linked systematic review [14].

Data were extracted from included studies using standardised tools developed by the Joanna Briggs Institute, and the findings presented in this article have been analysed thematically using a comprehensive framework for factors affecting implementation of health promotion interventions, adapted from the SURE (Supporting the Use of Research Evidence) framework for preparing policy briefs [16]. The analytical framework, which is described in detail in a paper by Smith et al. in this series, includes five 'levels' of factors that affect policy implementation (main stakeholders in communities, healthcare providers, other stakeholders, health service delivery factors and social and political factors) and provides a list of types of barrier and enabler for each level. One of the authors, $\mathrm{BMH}$, read through all included studies and extracted data relating to each level of the framework, then both authors examined the extracted data and re-organised them into themes based on the list of types of barrier and enabler.

\section{Results}

\section{Range and quality of the body of literature}

The article includes findings from 49 quantitative studies and from an additional 49 qualitative studies that contained information relevant to the quantitative studies (see Table 1 for details of included studies) that relate to the five types of DSF in 22 country programmes:

- conditional cash transfers (Brazil's Bolsa Familia [17, 18], El Salvador's Comunidades Solidarias Rurales [19], Guatemala's Mi Familia Progresa [20], Programa de Asignación Familia in Honduras [21], the Muthulakshmi Reddy Maternity Benefit Scheme in India [22, 23], Indonesia's Program Keluarga Harapan [24-26], Mexico's Oportunidades [27-34], and Plan de Atención Nacional a la Emergencia Social (PANES) in Uruguay [35]);

- unconditional cash transfers (Zambia's Child Grant Programme [36]);

- short-term cash payments to offset costs (CHIMACA in China [37], India's Janani Suraksha Yojana [38-74], the Safe Delivery Incentive Programme in Nepal [75-77] and the SURE-P programme in Nigeria [78]);
- vouchers for maternity care services (Bangladesh's Maternal Health Voucher Scheme [79-84], a pilot programme in Bangladesh [85], a voucher programme in Cambodia [86, 87], the Chiranjeevi Yojana in India [88-92], Kenya's Vouchers for Health programme [93-102], pilot programmes in Pakistan [103, 104], and the HealthyBaby vouchers $[105,106]$ and Mekerere University Voucher Scheme in Uganda $[107,108])$, and vouchers for merit goods (the Tanzanian National Voucher Scheme [109-111]).

Programmes ranged from small-scale pilot voucher schemes in Pakistan and Bangladesh to large national programmes such as Janani Suraksha Yojana in India, Bangladesh's Maternal Health Voucher Scheme and multiple conditional cash transfer programmes in Latin American countries. Programme design varied from those that were purely demand-side to those that included supply-side incentives such as output-based payments to service providers (for example many of the voucher programmes), or incentives for communitybased workers (such as in India's Janani Suraksha Yojana). Funding for programmes has come from national and state governments or from donor organisations such as the German Agency for International Cooperation (GIZ), the UK Department for International Development and the Bill and Melinda Gates Foundation.

The studies were generally of medium quality. Many of the quantitative studies were conducted early in the implementation of programmes and some made only limited efforts to account for confounding factors. Qualitative studies were often part of larger programme evaluations that focused primarily on quantitative outcomes and some of the articles reporting these findings lacked detailed descriptions of the methods used to collect and analyse data. Despite these limitations an overview of this literature does offer insights into the programmatic processes across a wide range of DSF initiatives and allows us to identify common features across programmes as well as some programme specific challenges.

\section{Stakeholder perspectives and experiences}

Three groups of stakeholders in DSF programmes have been studied in most detail: women service users, community-based workers, and staff in health facilities. Documented experiences from each of these groups are reviewed below and relate to awareness of programmes, cultural attitudes, perceptions of maternity care services, reasons for using or joining programmes and the challenges faced during participation. Many findings reflect wider issues in healthcare systems, however this section focuses on DSF implementation, and findings have been disaggregated by type of DSF where possible. 


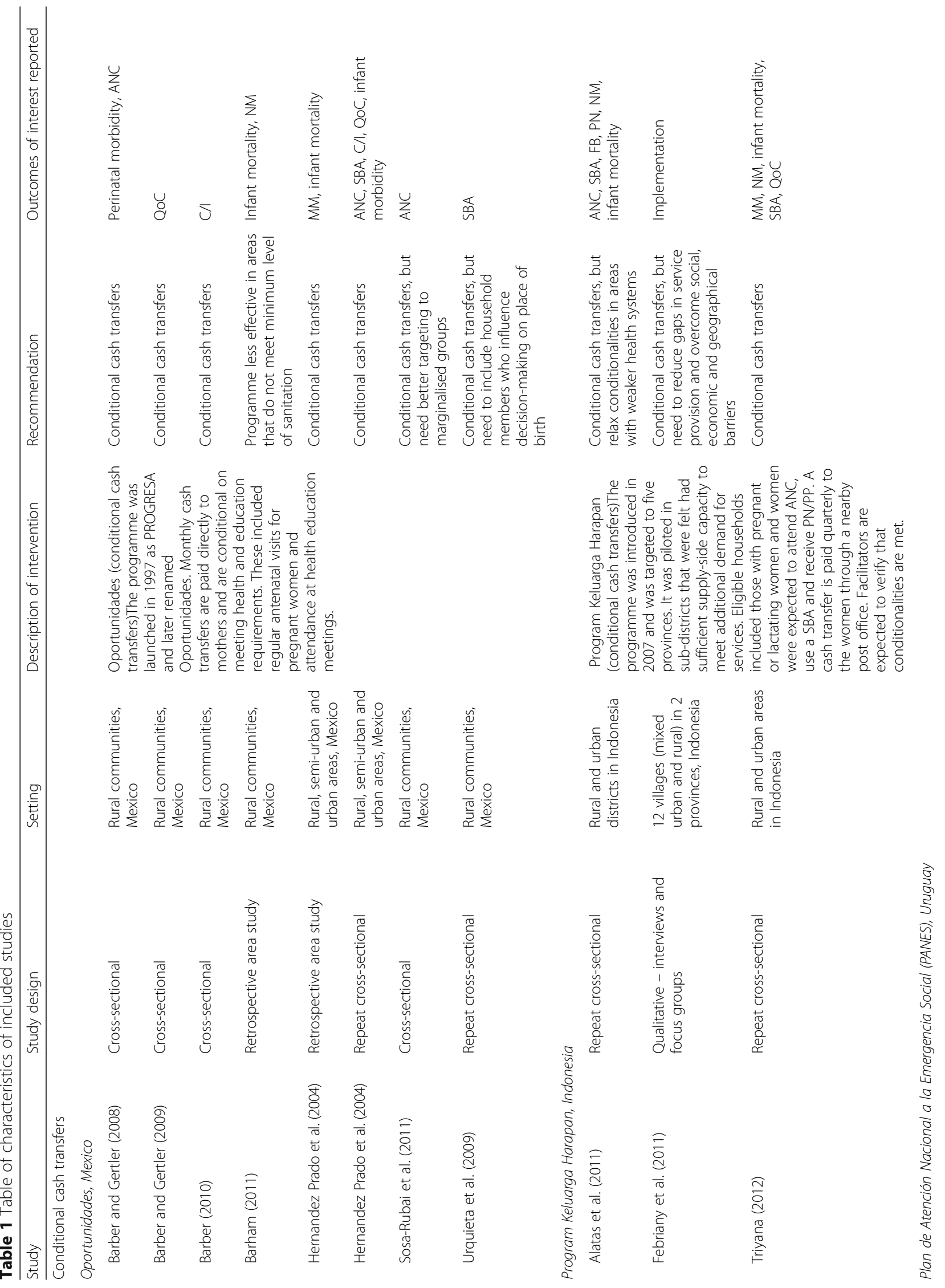




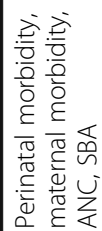

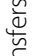

吾

중

:

仓ั่

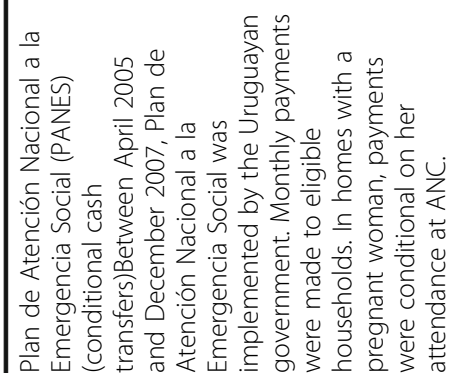

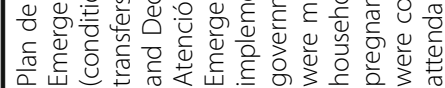

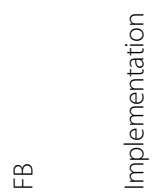

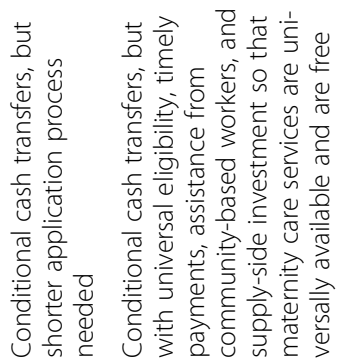

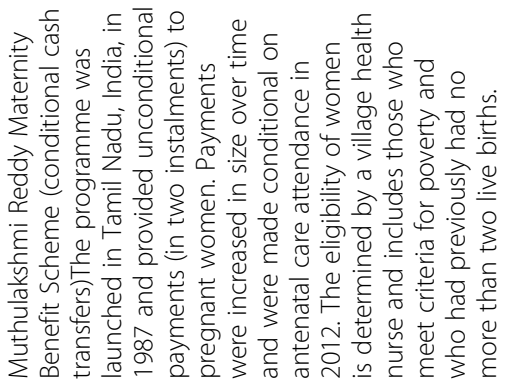
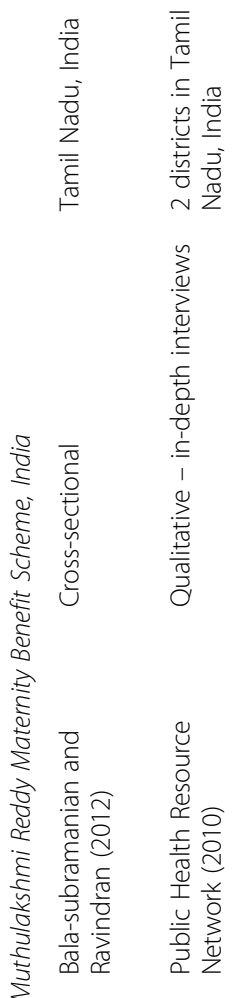

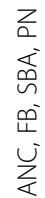

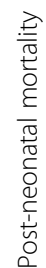

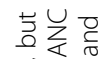

产

焉

约

응 요휼

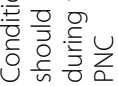
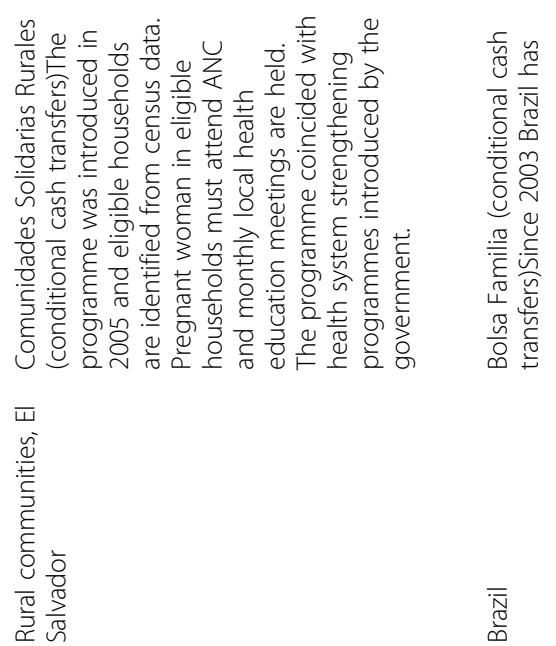

$\underset{\substack{\overline{0} \\ \text { D্ }}}{ }$

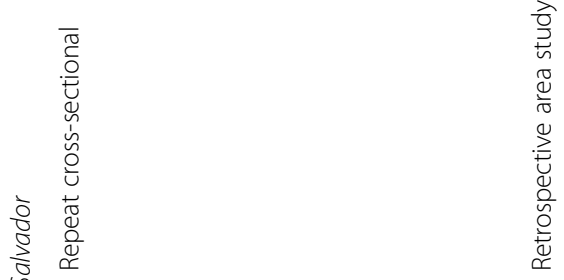

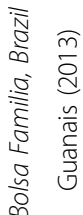




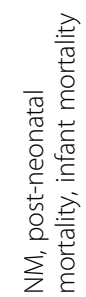

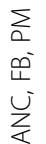

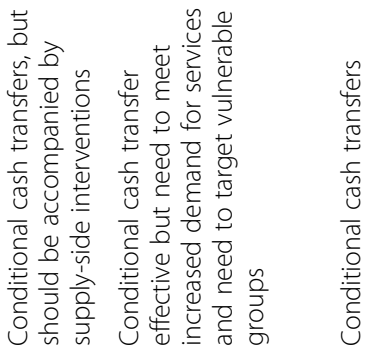

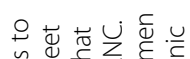

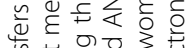

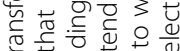

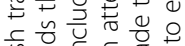

שֶ

入े

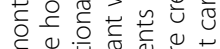

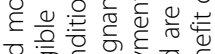

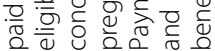

$\underset{\bar{N}}{\bar{D}}$

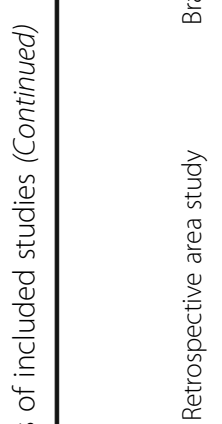

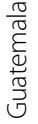

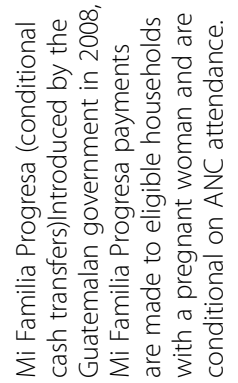

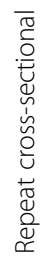

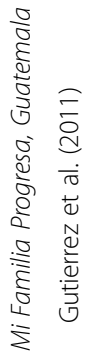

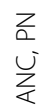

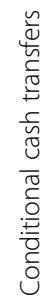

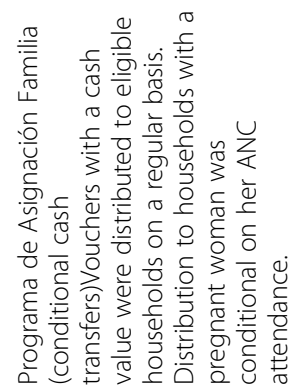

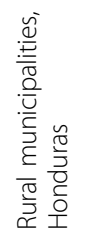

$\overleftarrow{1}$

பั

这

몰.
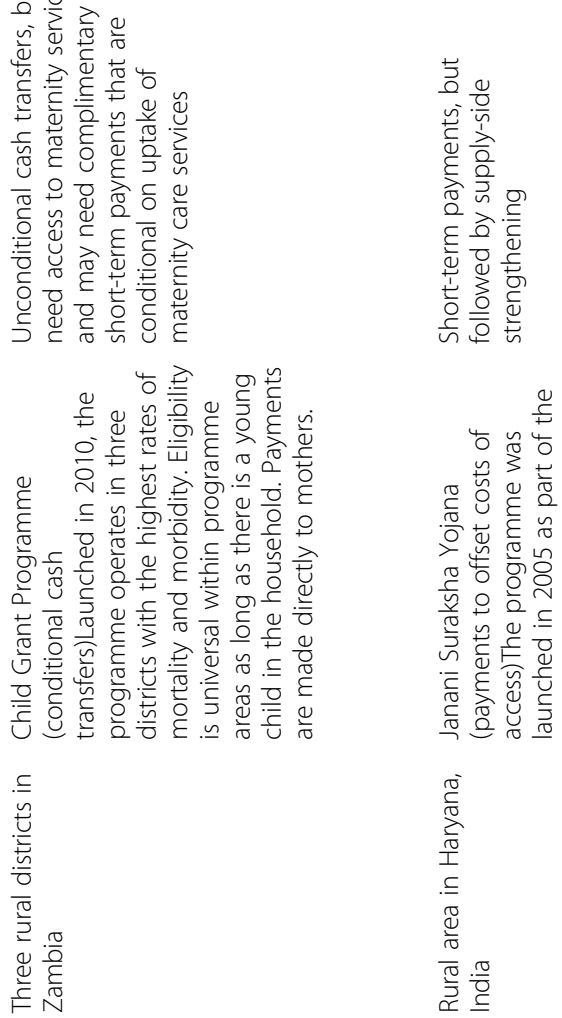

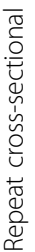

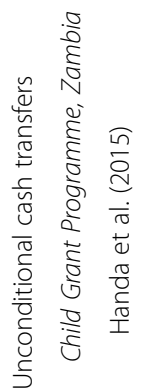

\begin{tabular}{ll} 
& $a$ \\
\hdashline & $\grave{a}$
\end{tabular}

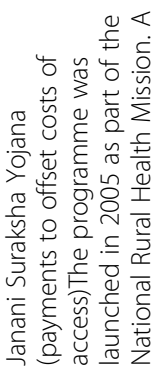

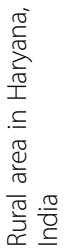

윰

这

焉

亗

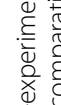

শ ठำ

预苍高苍

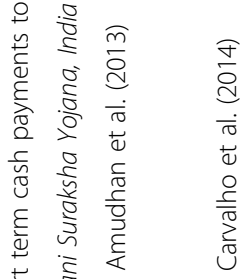



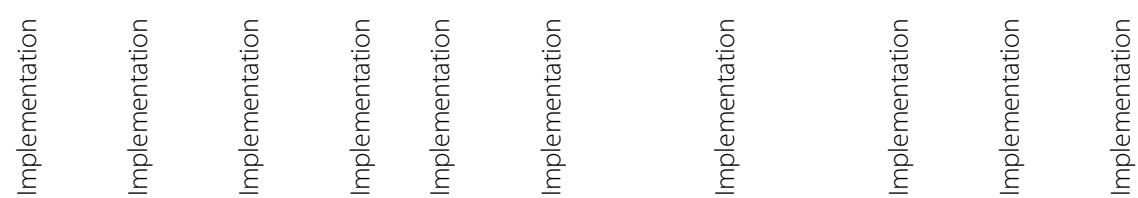

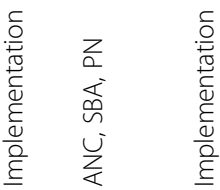

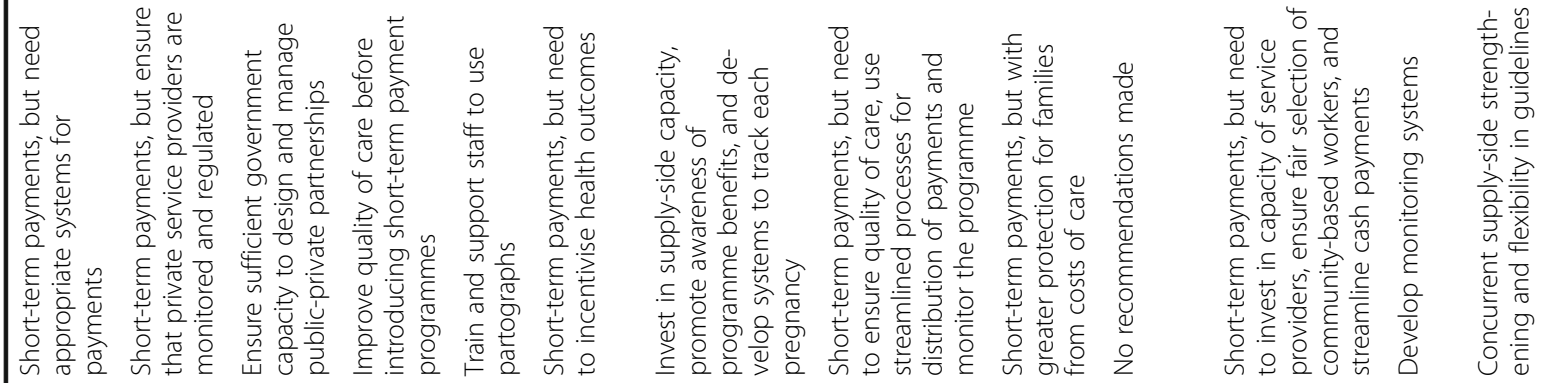

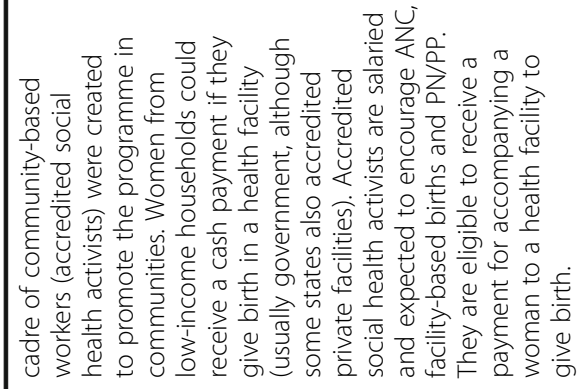

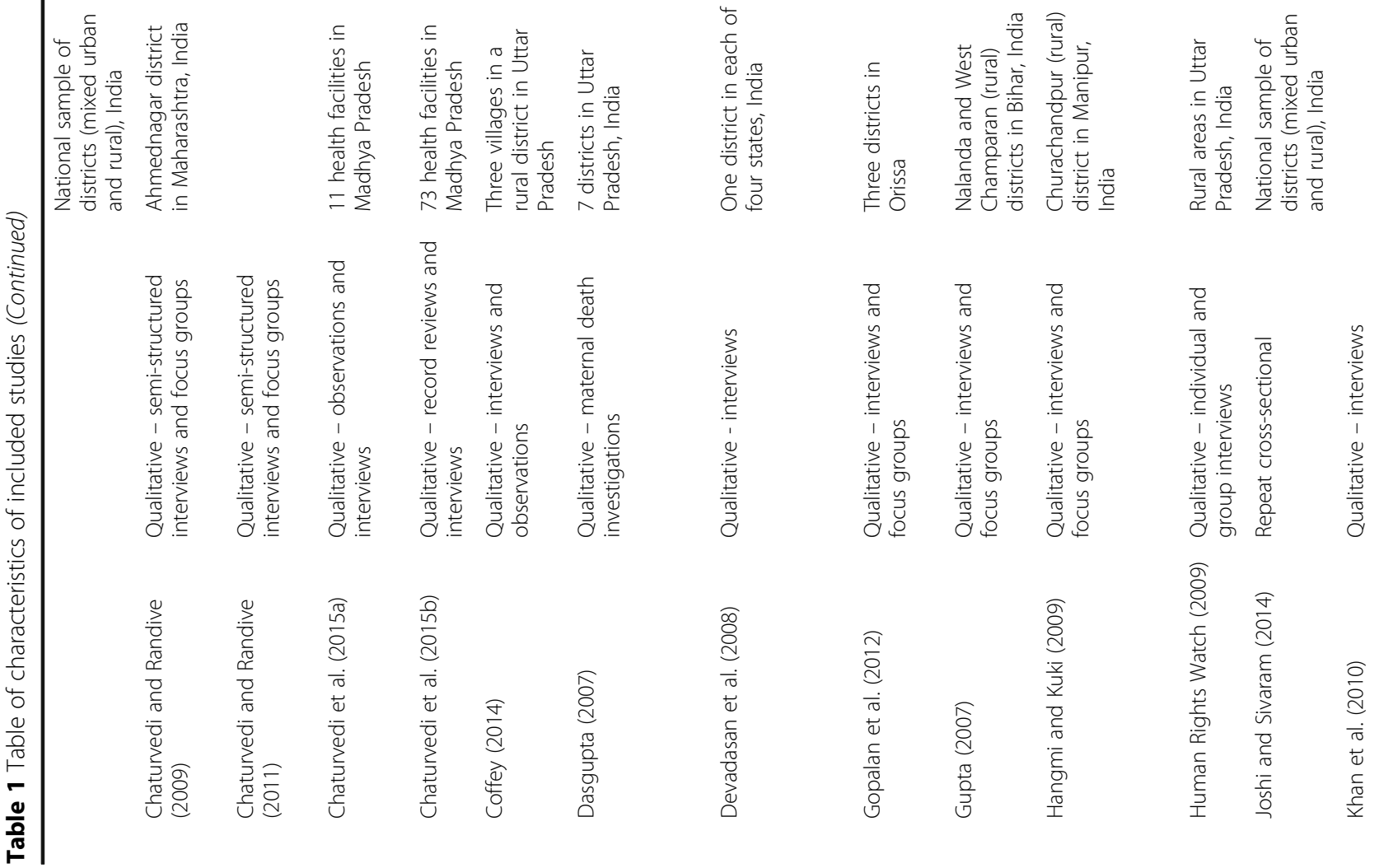




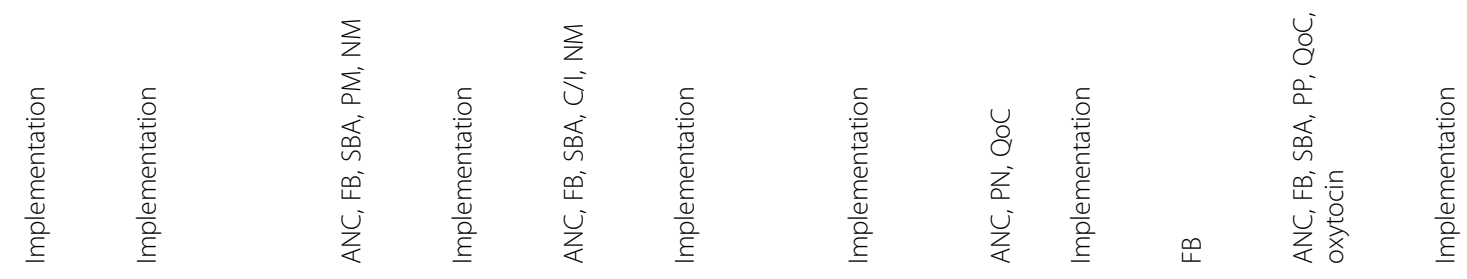

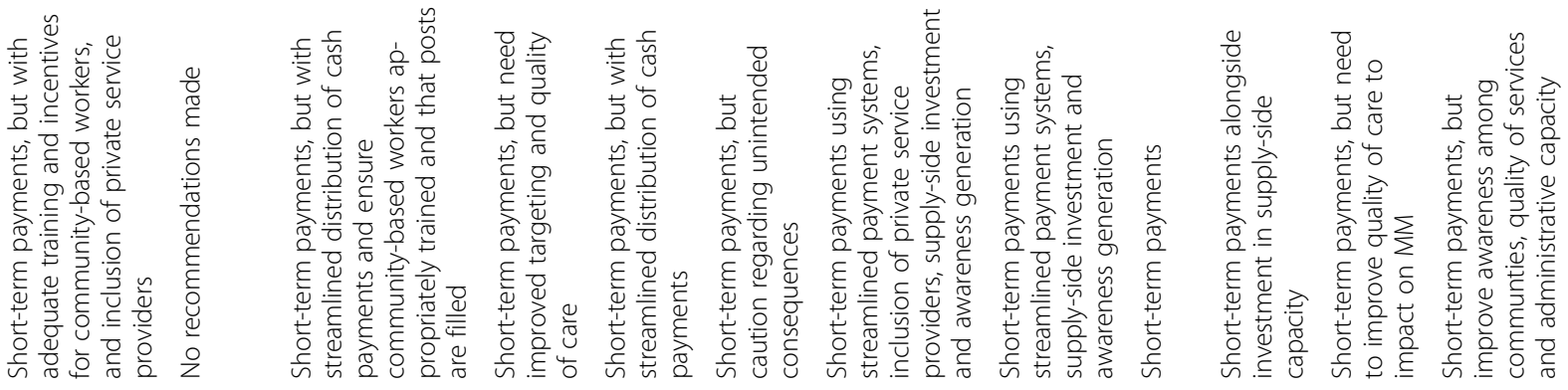

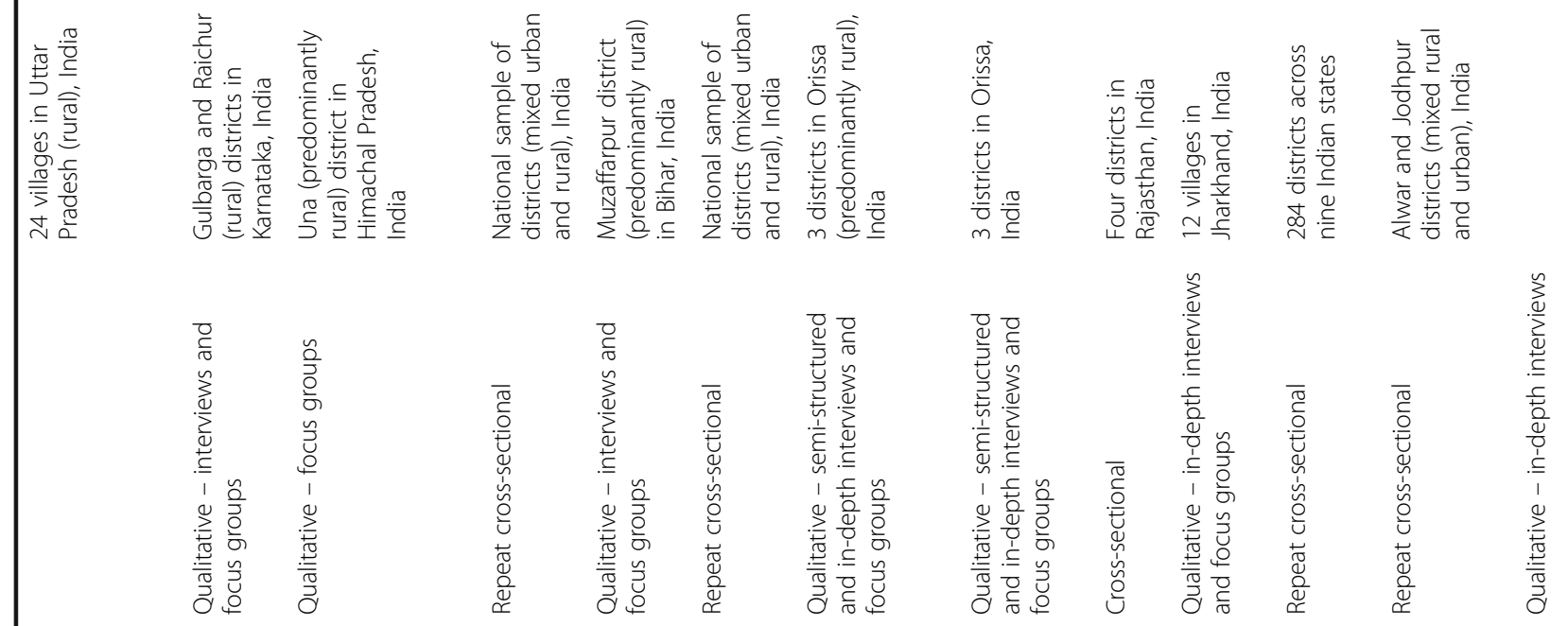

\begin{tabular}{|c|c|c|c|c|c|c|c|c|c|}
\hline 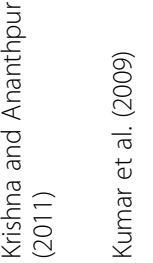 & 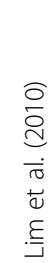 & 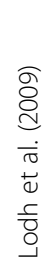 & 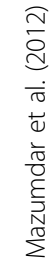 & 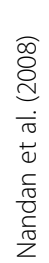 & 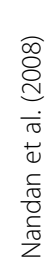 & 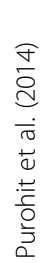 & 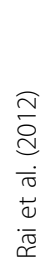 & 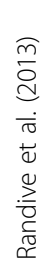 & 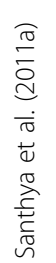 \\
\hline
\end{tabular}




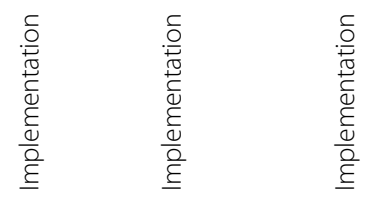

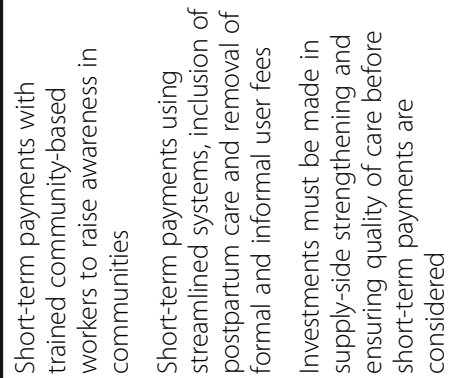

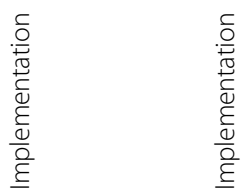

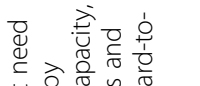

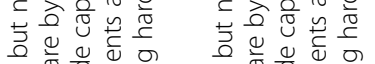
ज它谅

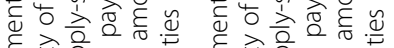

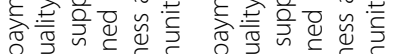

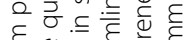
$\xi$
$\bar{v}$

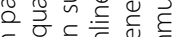
$\xi$ 政

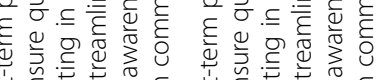

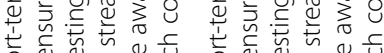
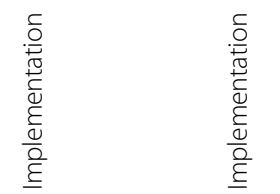

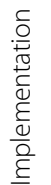
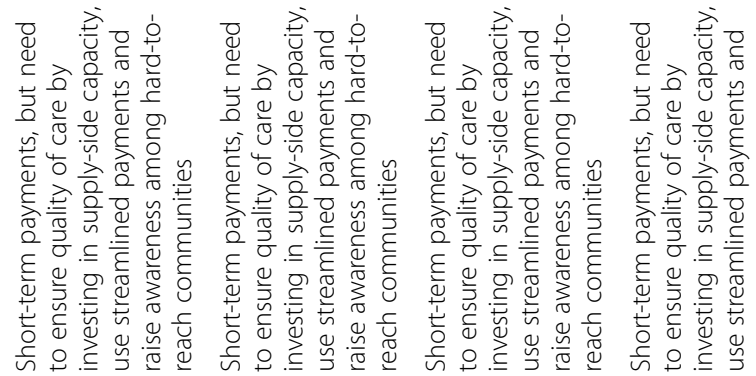
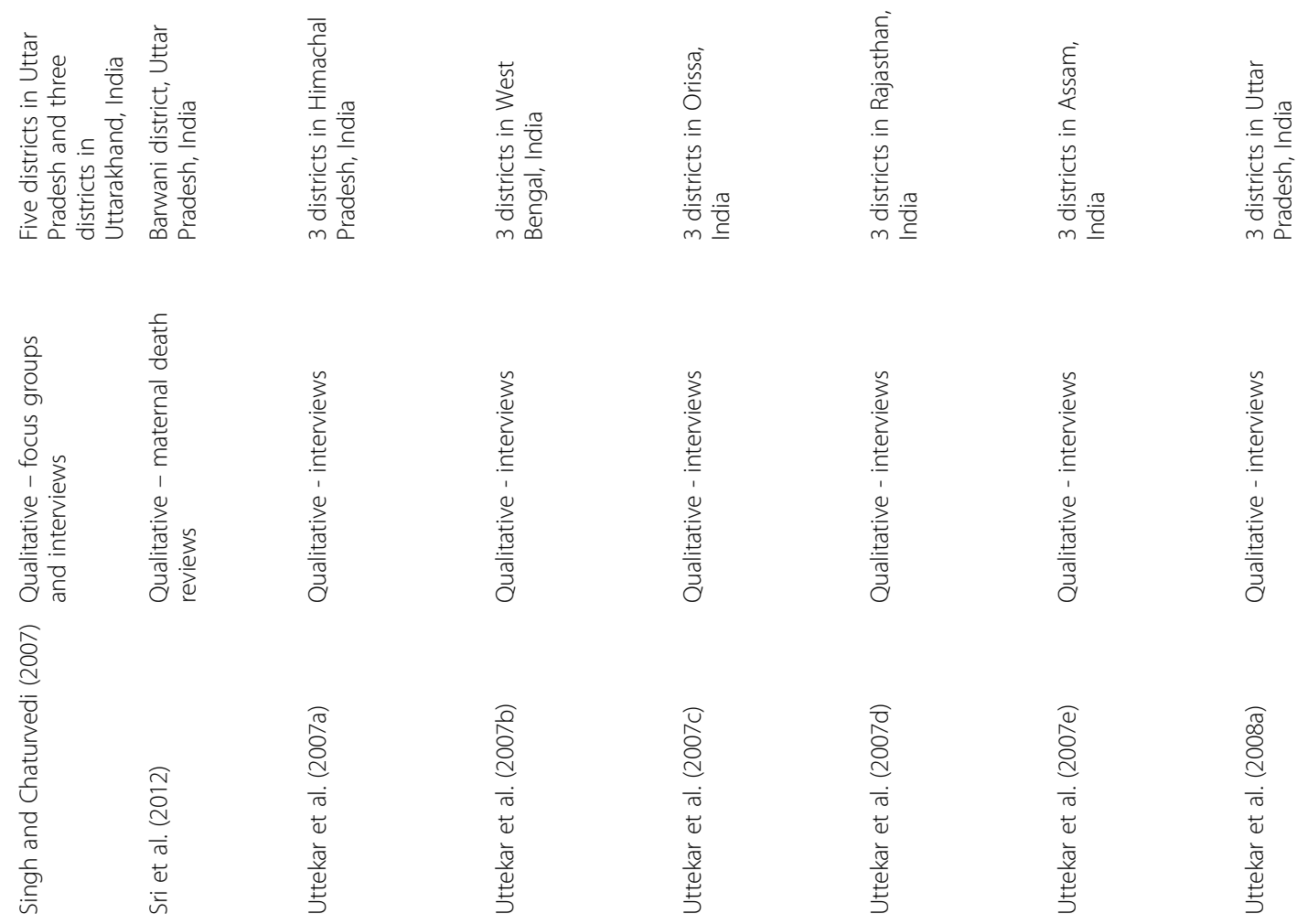

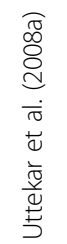



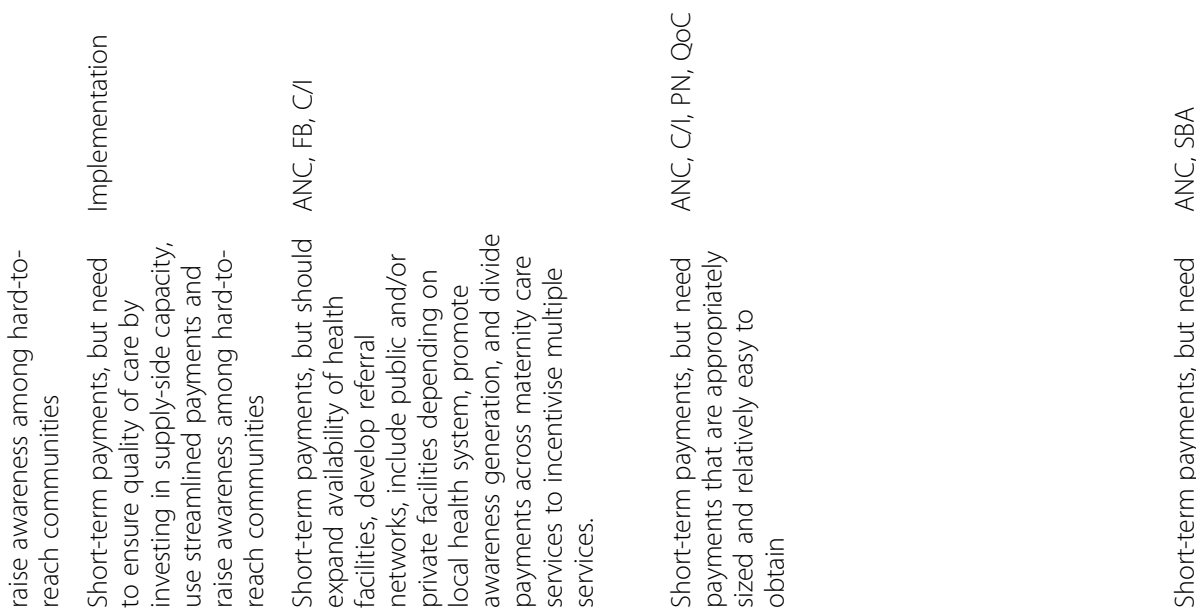

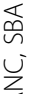
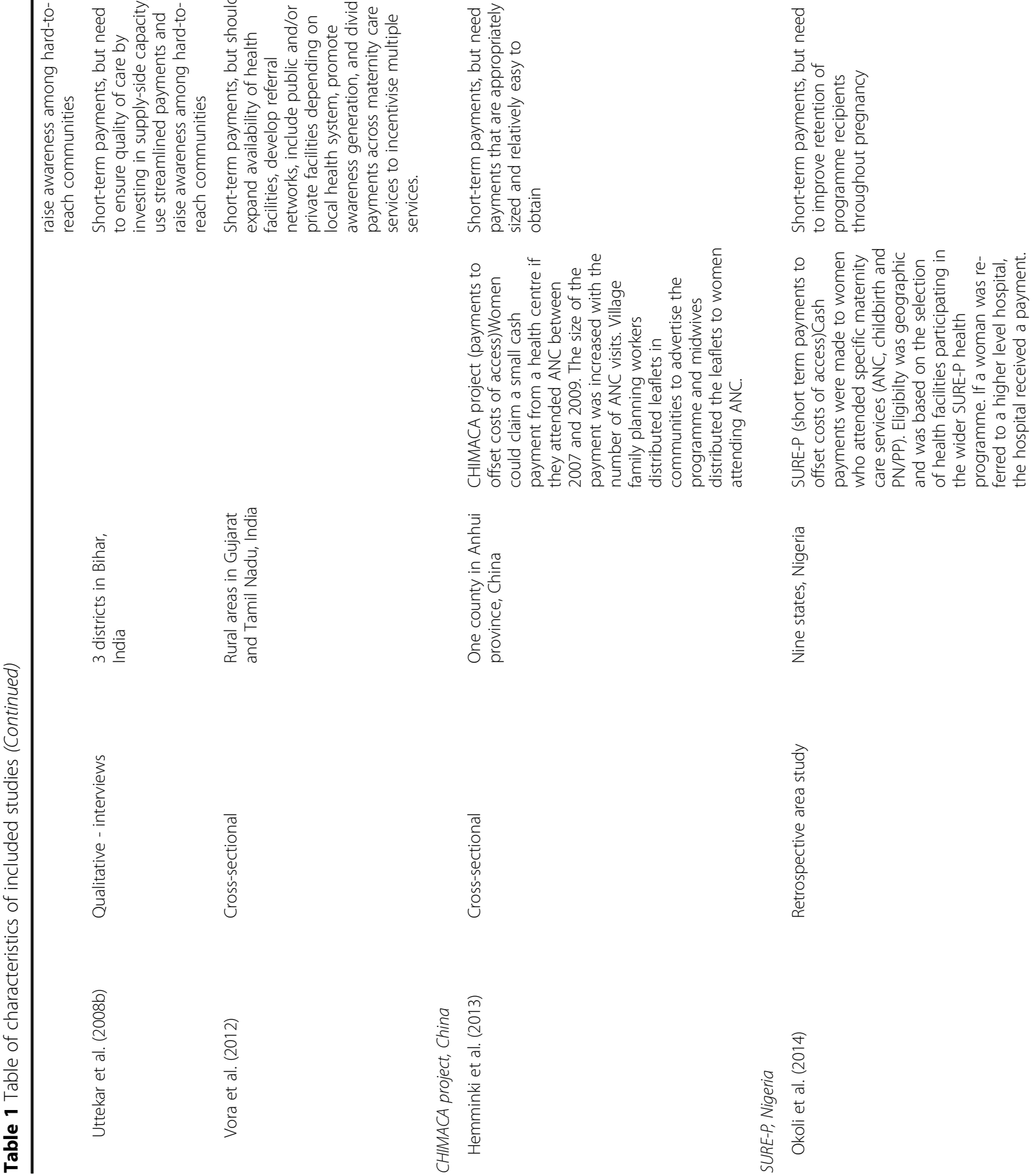

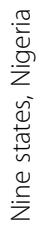

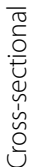

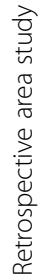

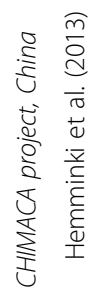

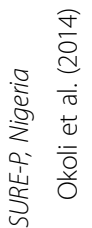




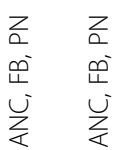

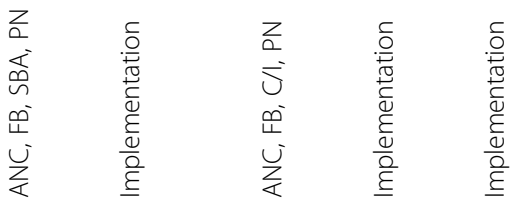

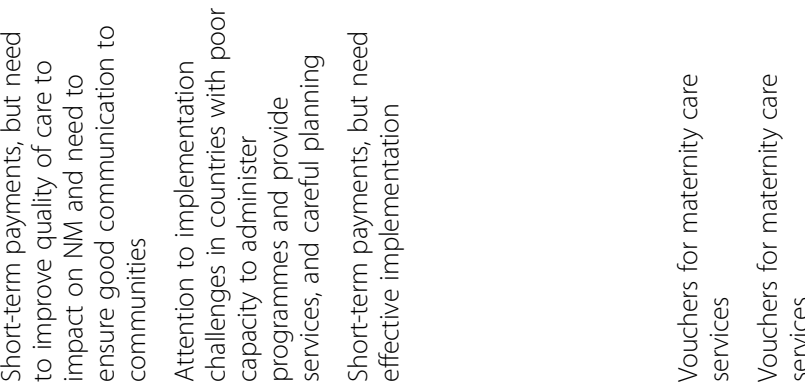

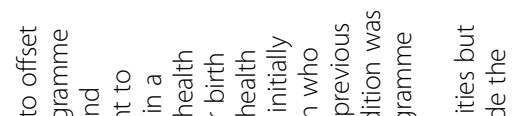

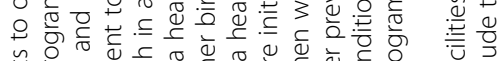

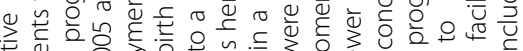

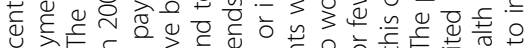

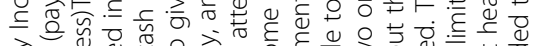

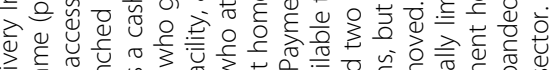

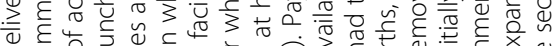

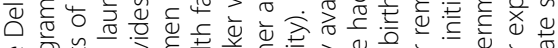

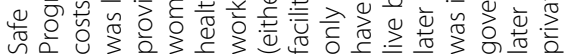

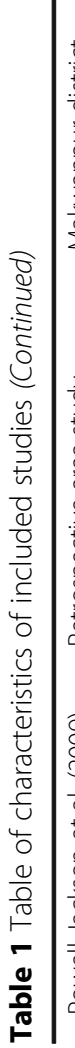

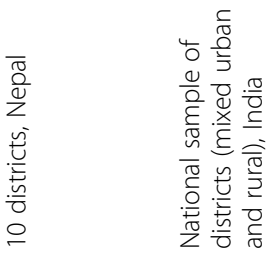

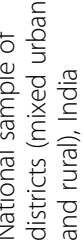

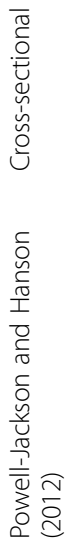

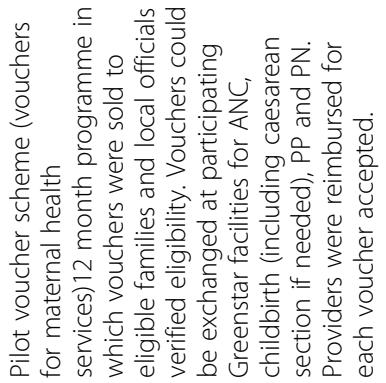

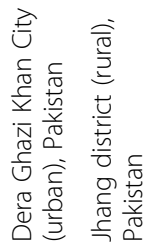

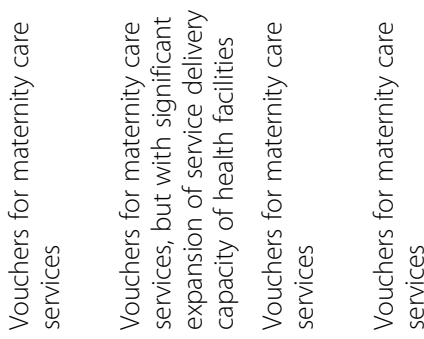

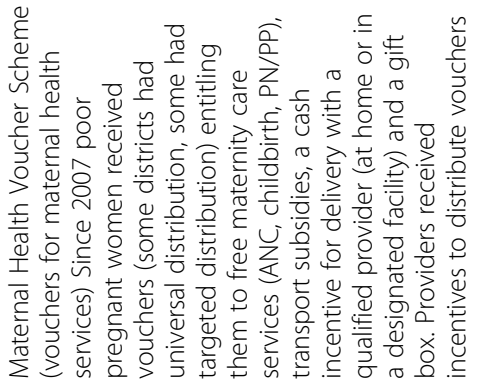

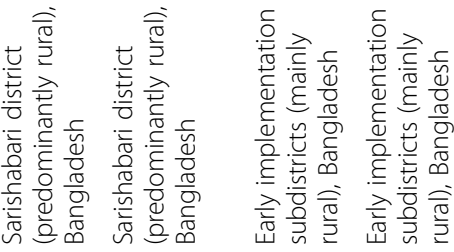

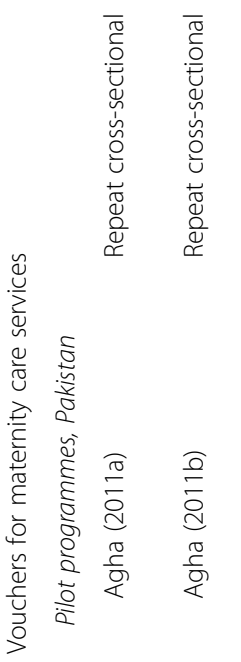

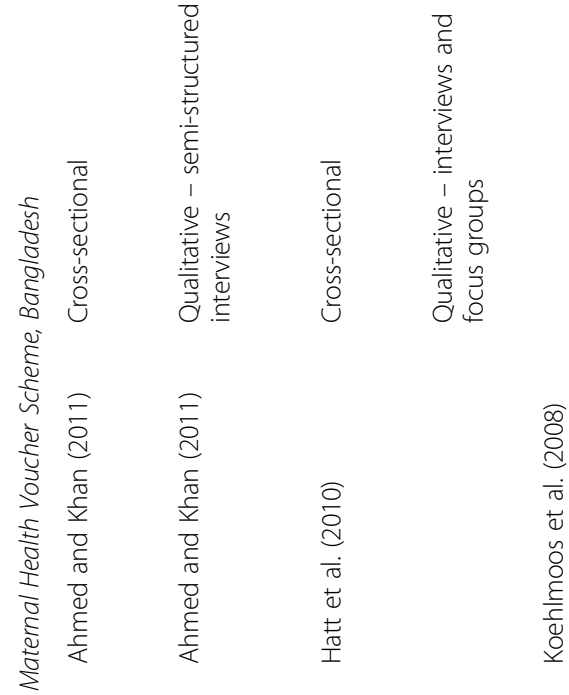




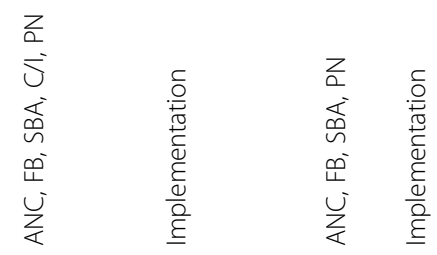

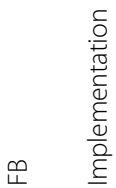

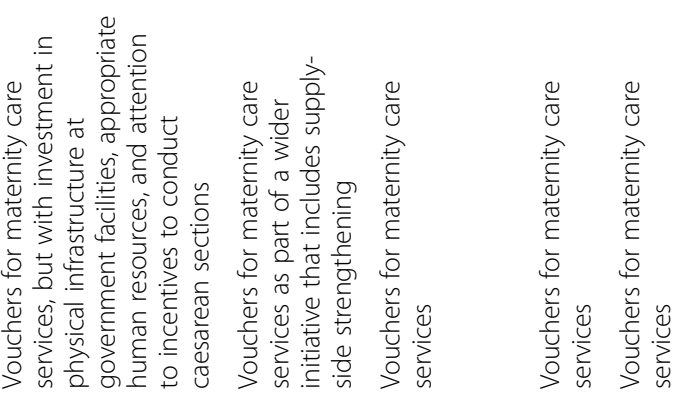

$\frac{0}{\stackrel{2}{3}}$

茫

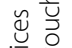

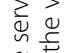

을 을

을 원

둥 己

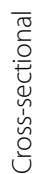

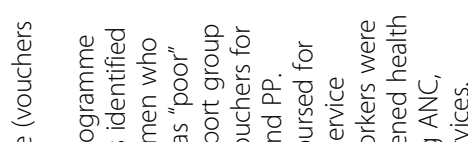

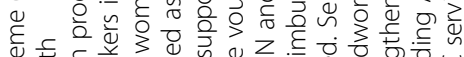

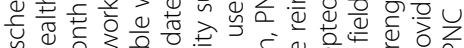
论

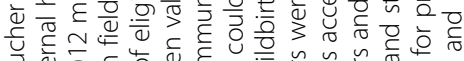

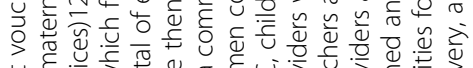

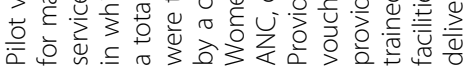
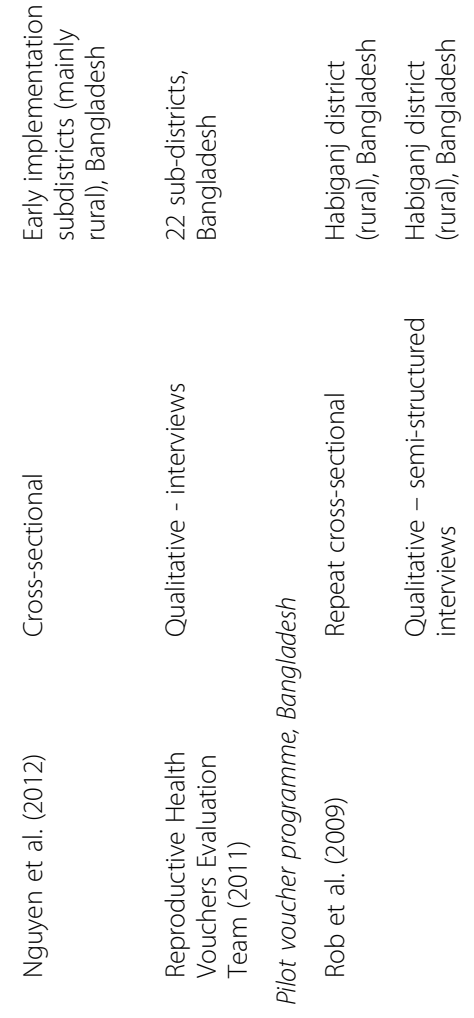
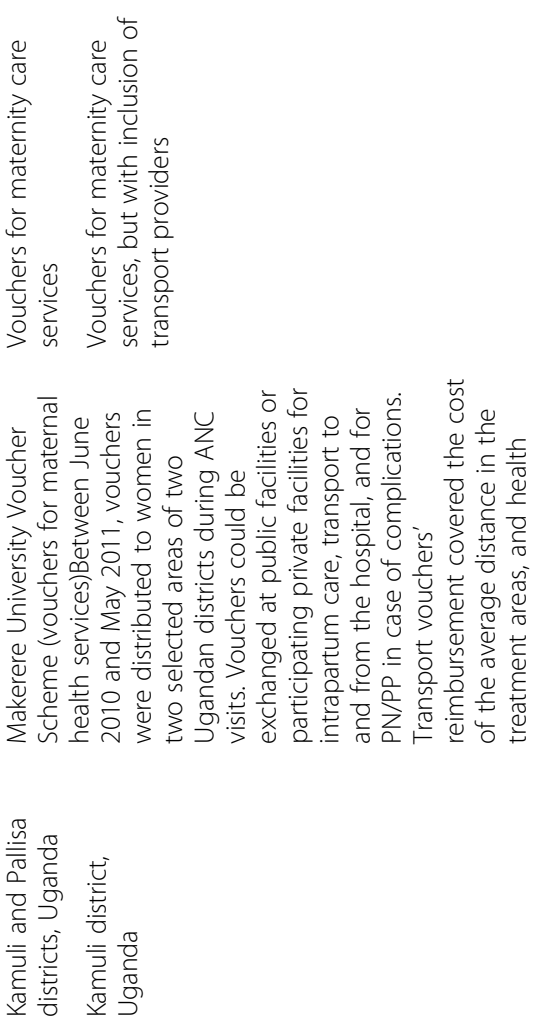

ह

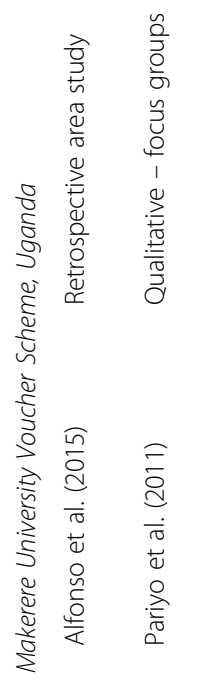




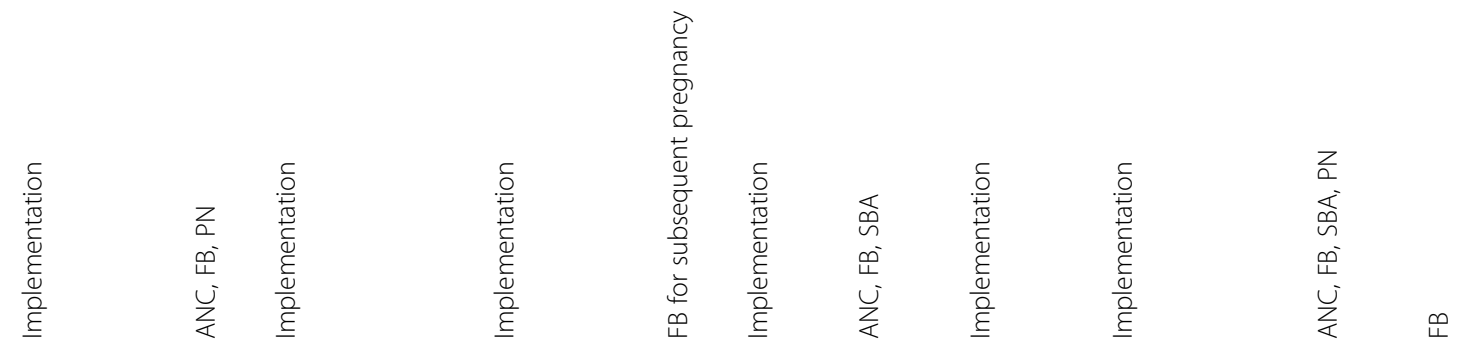

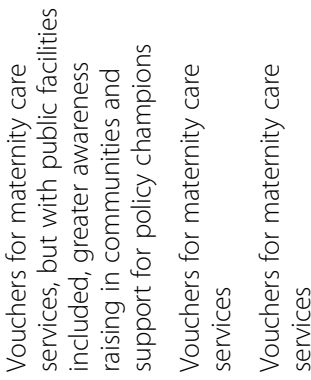
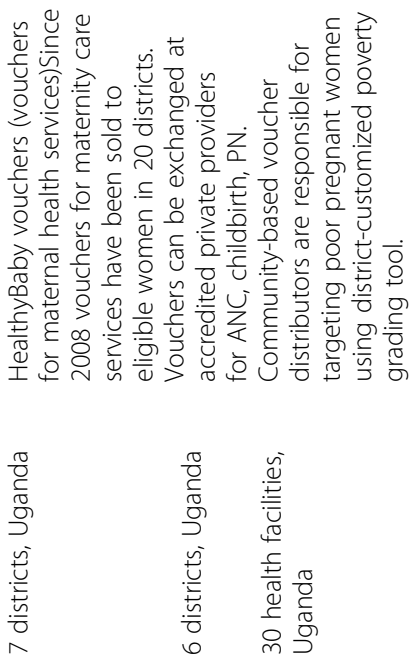

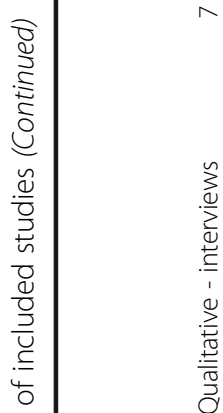
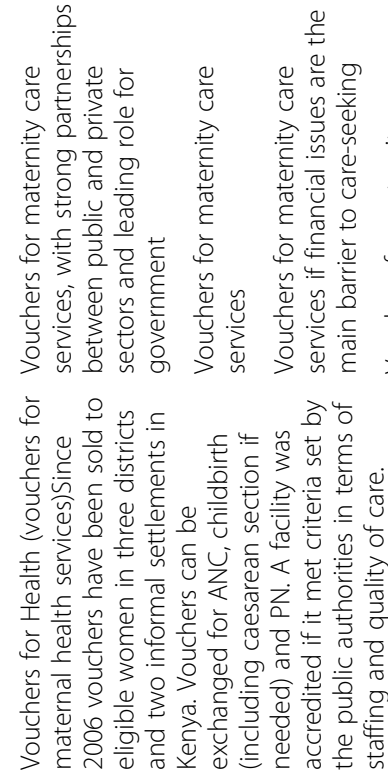

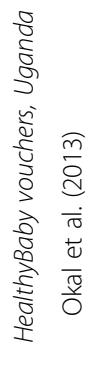

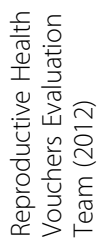

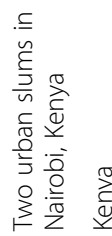

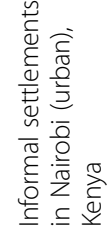

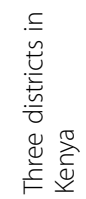

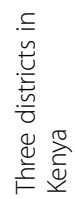

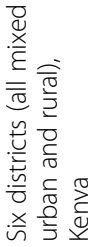
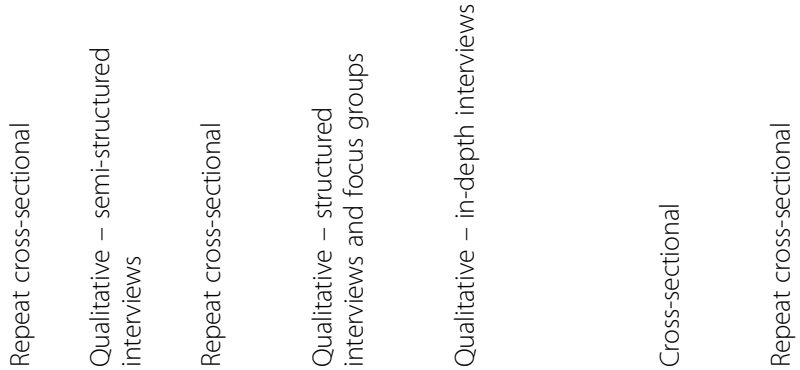

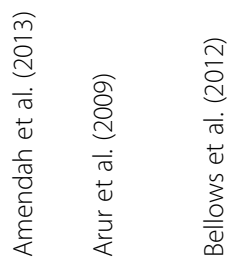

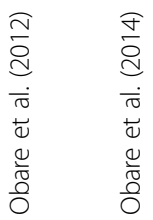




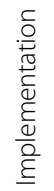

¿

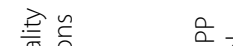

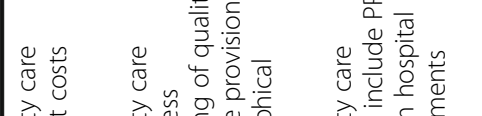

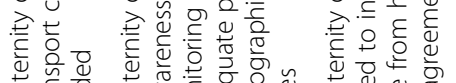

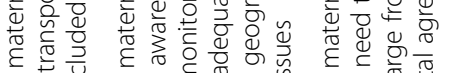

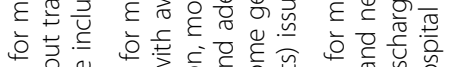

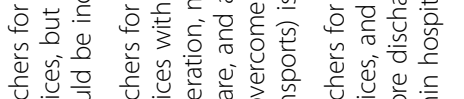

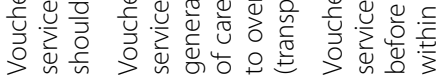

7

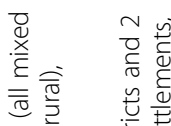

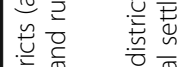

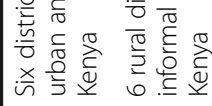

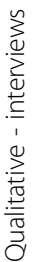

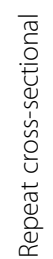

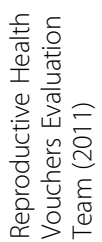

z. ๑

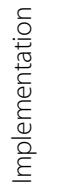

$z$
$a$
$S$
0
$0^{-}$
$u$
$z$
$z$

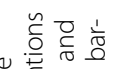

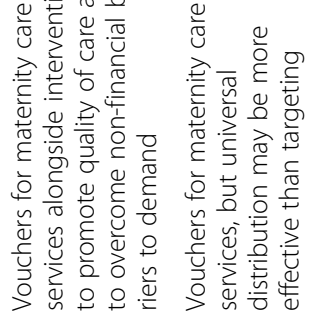

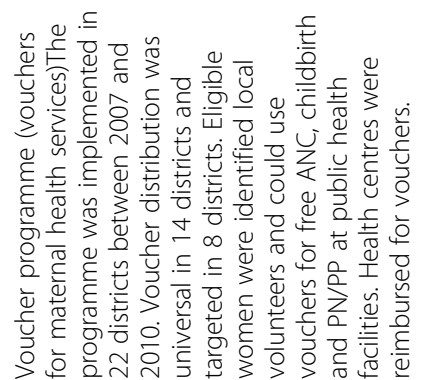

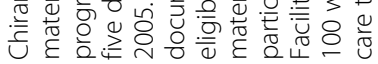

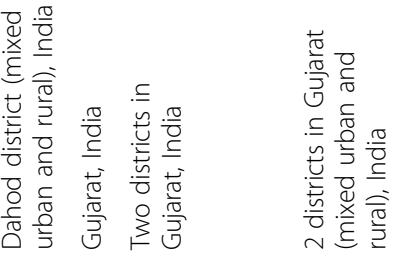

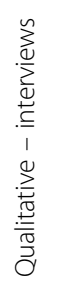

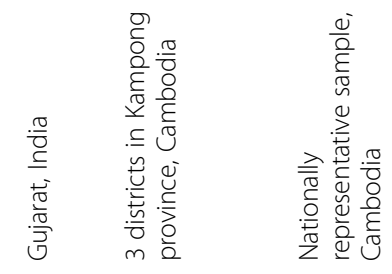




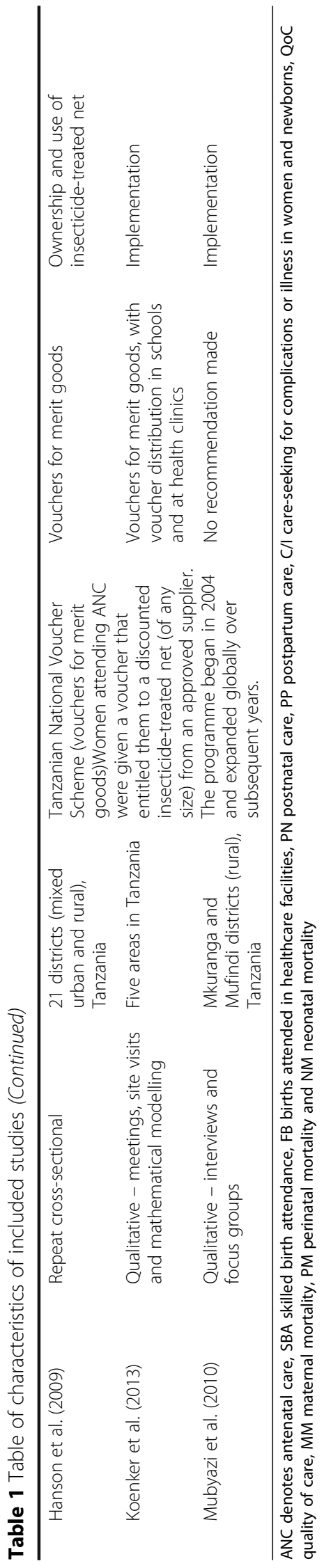




\section{Women who are potential DSF programme users}

Target groups may be unaware of programme details $[24,25,41,46,50,58,59,61,63,64,67,71,76,77,81$, $85,89,91,98,101]$. Women and their families may not realise that they are eligible for programmes (or incorrectly think that they are) and may not know which facilities they can use through the scheme $[48,63]$. Remote areas may be less likely to receive promotional activities [93, 101]. Effective forms of awareness generation have included community dissemination of information [81], radio broadcasts [93], and networks of women's groups [19, 28, 29, 77].

Social and cultural attitudes towards women play an important role in utility of vouchers as well as in use of services. Some women reported not being able to use a voucher because their husband did not want to be labelled as poor $[98,105]$, because they were expected to return to a family home elsewhere to give birth [105], or because nobody was available to accompany them to a participating hospital [63, 71, 85]. Of those who did travel to facility for birth care, many sought early discharge in order to return to look after children [52].

Perceptions of the quality of care and behaviour of providers were important for utilisation of health services, and therefore the implementation of DSF schemes. Prospective users were discouraged by reputations that facilities had long waiting times $[81,85]$, were poorly equipped and unclean $[39,49,58,61,63,65,71,80,85,92]$, or were places where one encountered disrespectful and abusive care $[33,44,49,50,52,54,56,61,63,81,86,94,101,105]$. Modesty rules made some women reluctant to be treated by male doctors [58] or to visit midwives where it is considered inappropriate to let someone else see one's genitals [25]. Other deterrents included fear of being subjected to unwanted procedures such as injections, surgical procedures and stitches $[61,71,72]$ and of testing for HIV at a health facility and the attached stigma of HIV $[98,101]$. Regular antenatal care visits may help women to become familiar and more relaxed with facilities and staff [52], and community visits by staff and women who were satisfied with their care could promote uptake [71, 73].

\section{Community-based workers}

Workers based in communities (including voucher distributors) can be important facilitators for DSF programmes. India's accredited social health activists (ASHA) were found to be have played an important role in raising the awareness of Janani Suraksha Yojana and assisting women to obtain payments $[38,39,52,56,58$, 63, 64, 68-70, 72, 112], as did workers for Program Keluarga Harapan in Indonesia [24, 25]. Community health workers were an important source of information on DSF programmes in India $[64,88]$ and Tanzania
[109], and voucher distributors performed a similar role in Kenya [99], Pakistan [103, 104] and Cambodia [87].

Community-based workers occupy a challenging position between communities, DSF programmes and health facilities. In communities, they can face criticism and accusations of theft if cash transfer payments are delayed [23], or if women go to a facility to give birth but do not receive payments they had been told about, or receive a smaller amount than expected [49, 56, 58, 65]. When visiting facilities, community-based workers who are reimbursed for facilitating DSF programmes may be asked for informal payments by facility staff $[50,56]$. They may be used as go-betweens to request money from families on behalf of service providers and service providers have reportedly punished those who resist by refusing to register the facilitator's subsequent service users, referring them to other facilities unnecessarily, or withholding DSF payments $[44,50,56]$. In some cases women have been reluctant to allow workers to accompany them to a facility because they feared money would be taken from them [48].

The potential of community-based workers to implement DSF programmes can also be undermined by geographically over-large operating areas that entail long distances for travel [25]. Some female workers were restricted by their family members in when they could accompany pregnant women to a facility [56]. Some workers' usefulness was limited by their poor knowledge of programme details [53] and others reported difficulties in applying eligibility criteria because their guidelines were not clear [23]. Financial issues included resistance to their continued work for the programme from their families if their payment was delayed [56], and having to pay for food and transport when accompanying a women for antenatal care yet not receiving any reimbursement if the woman later gave birth at home $[47,56,58]$. Other difficulties include the risks of co-option of schemes by community members for personal gain. Positions as programme workers are sometimes regarded by communities as 'lucrative' compared to other forms of work [44], and there have been reports of recruitment processes being hijacked by local politicians and community leaders to appoint family members even though they were unlikely to want to perform the necessary duties $[48,65]$.

\section{Staff in health facilities}

Experiences among service providers and managers at participating health facilities seem to be mixed. In evaluations of voucher schemes, government and private providers report gaining skills and experience, making investments in infrastructure, being able to hire more staff, and reduced absenteeism among existing staff $[86,106,108]$. However, staff at some facilities in voucher schemes felt that increased userload and administrative work was not adequately 
compensated by provider payments [79, 82, 106]. Some felt that schemes designed to target specific groups created problems and complained that they had been threatened by women who were excluded by meanstesting criteria [81], or subjected to pressure from local politicians to distribute vouchers to ineligible women [81].

In short-term cash payment programmes, service providers at government facilities reported a significant increase in their workload exacerbating the existing inadequacies of services $[40,46,50,54,59,61]$. Knowledge of schemes varied. Some government providers in India admitted that they knew nothing about Janani Suraksha Yojana other than that they needed to give payments to women who gave birth in the facility [54, 59]. One study reported that women were treated with hostility by facility staff when they sought cash assistance [54]. On the other hand, delayed or irregular reimbursements by programmes could lead to difficulties distributing money to women and expose the service providers as targets for criticism from families $[48,76]$.

In programmes designed to allow opt-in of private providers, respondents reported that they joined to help the poor to access health services $[81,90,91]$ and conversely to increase business $[81,90]$. In one study some said they felt coerced, fearing that they would otherwise be subjected to unwarranted but damaging investigations [90]. Private providers reported subsequently dropping out of voucher schemes because they felt 'overwhelmed' by the number of voucher users [93], or were unhappy with inadequate and delayed payments [108]. Some private providers in the Chiranjeevi Scheme in India reported that revenue had fallen because there were too few voucher users, their facility had gained an unwanted reputation as a place for poor people, and that pregnant women who used to pay fees to be attended there were now using the voucher programme [90]. Providers in the Tanzanian National Voucher Scheme for insecticide-treated nets stated that they enjoyed participating but that the programme required substantial investment of money and storage space to stock slow-selling nets, at the expense of other more popular items such as soap [110].

\section{Barriers and facilitators to successful implementation}

Seven themes were identified regarding barriers and enabling factors for the implementation of DSF programmes: scope of the programme, supply-side capacity, contracting private providers, administrative processes and procedural considerations, information systems, fraudulent practices and their control, and sustainability issues.

\section{Scope of the programme}

A common barrier found across many DSF programmes was that they were insufficient in their scope to overcome continued financial, social and geographical barriers to accessing services. Vouchers for maternity care services typically cover treatment costs but many do not include other important 'demand-side' costs such as transport, which can be prohibitive for households $[79,85,88,92$, 96, 98-101, 104-106]. There is also the opportunity cost for women and their families of spending time away from their home and children $[86,103]$. In contexts where pregnant women are asked to buy vouchers, for example the Vouchers for Health programme in Kenya, women may be deterred by the price of vouchers $[96,100]$. Experiences with vouchers for merit goods in Tanzania have been similar. Women highlighted the cost of travel to obtain a voucher from health facilities, the cost of travelling to an approved shop to use the voucher and the remaining cost of the insecticide-treated net (which was only partsubsidised by a voucher) $[109,111]$.

Possible options to increase the accessibility of voucher services include, inclusion of travel costs within voucher entitlements [80, 81, 85, 100, 107], community distribution of vouchers to reduce travel to obtain a voucher and accreditation of additional facilities and providers to reduce travel to make use of a voucher [105]. For example, the Maternal Health Voucher Scheme in Bangladesh included short-term cash payments to facilitate uptake by offsetting costs of access [79].

In short-term payment programmes and in cash transfer schemes, payments may simply be too small or too late to offset out-of-pocket costs that include transport, tests, medicines and sutures $[23,25,33,37,44,46-49$, $54,55,58-61,66,67,77]$. The size of payments may need to be increased periodically to keep pace with inflation and the Muthulakshmi Reddy Maternity Benefit Scheme in India has repeatedly increased the amount paid to women during its 30 year implementation period [22]. The programme offered 300 rupees to eligible women when launched in 1987 and now offers 12,000 rupees (approximately USD 190).

Provisions for onward referral in the case of an obstetric complication have often not been included in DSF schemes yet should be considered (see also sections on supply-side capacity and on procedural considerations below). Some families reported having to pay for treatment costs after they were referred to a non-participating facility [101], and others returned home when faced with additional expenditure [54, 66]. Bangladesh's Maternal Health Voucher Scheme included 'seed funds' that could be used by health facilities for supply-side investments and to pay for emergency transport for voucher users [81].

Narrow eligibility criteria were highlighted as a barrier by studies of many DSF programmes. For example, schemes that exclude women who have more than a certain number of children are reported as unfair, difficult to enforce and completely counter-intuitive for programmes 
that aim to reduce maternal mortality $[22,76,79,82]$. If a decision is made to design a targeted programme then use of locally appropriate poverty screening tools should be considered [94, 95, 98, 99, 101, 106]. Programmes in India have often used an existing system of 'below poverty line' cards however such programmes are constrained by any pitfalls in the existing system such as non-ownership of cards by those in need but lacking documentation, and leakage of cards to those least in need [88].

\section{Supply-side capacity}

The contextual evidence highlights that DSF cannot work well without adequate supply-side investment in public services and systems, and many of the findings in this sub-section are indicative of wider challenges in healthcare systems. Many evaluations of DSF programmes described problems at health facilities as a key barrier. Poor availability of medicines and other medical supplies - sometimes linked to bureaucratic procedures for procurement that discourage restocking [48] - meant that women in Bangladesh and India needed to make considerable personal expenditure [81, 82, 85]. Bed shortages meant many women were discharged within $24 \mathrm{~h}$ of giving birth, which may not allow sufficient time for post-partum care $[46,48]$. In Indonesia's Program Keluarga Harapan, cash transfers were contingent on using midwives however village midwife posts were reported to be unfilled in many areas [25]. Contracting private providers in voucher schemes does not remove the need for quality public sector provision as private providers often refer complicated cases to the public sector [105].

In India, where DSF schemes can be found in many states, there have been widespread reports of poor quality of care and improper practices, linked to increased workloads of staff in health facilities $[40,55,60,63]$. It is important to monitor quality of care and adverse outcomes after childbirth, however DSF programmes were reported to lack adequate monitoring systems in this area $[45,46,50]$ and women reported having no way to register and process their complaints at health facilities $[50,66]$. Incidents included delays in starting treatment for women with serious conditions [66], chaotic delivery rooms [40], low utilisation of partographs [43], babies being left unmonitored in birth pans [44], physical abuse of women $[44,66]$, episiotomies conducted without permission and stitched without local anaesthesia [44], high incidence of oxytocin injections for labour induction [45], and pregnant women who have been diverted from a public to a private facility at the behest of an owner who worked on-call at the public facility [41].

Referrals from one facility to another are a key issue that may put the life of the woman and her baby at risk and are a cause of substantial expenditure for families who face additional costs for transport, food and accommodation $[41,45,50,53,54,66,70,76,79]$. Reported reasons for referral related to wider healthcare systems issues including absence of specialists at lower level facilities [42, 50, 59, 79], busy or absent doctors and midwives [49, 50, 58, 62, 66, 67], and a lack of functioning equipment for operations or blood transfusions (including faulty or stolen generators) [40, 48, 50, 65, 91]. In India, private practitioners in the Chiranjeevi Yojana were reluctant to provide care for clusters of women requiring care for complications due to the associated costs and the risk of adverse outcomes [90, 91].

There are two key enabling factors for programme designers and managers to support facilities and promote care-seeking. Firstly, designers need to realistically examine the capacity of local health systems to provide care to women who use DSF programmes. This needs to include emergency transport [62], round-the-clock opening hours $[38,60]$ and clearly stated guidelines for onward referrals $[45,50,66,69]$. Procurement systems for essential medicines may need to be included within programme designs, at least until government procurement systems can be adequately strengthened [101].

Secondly, designers may consider how best to support participating facilities to maintain and improve the quality of care. Concurrent supply-side investments can improve working conditions for staff and expand service coverage, and 'seed funds' have reportedly been used to good effect in Bangladesh's Maternal Health Voucher Scheme [81]. El Salvador's Comunidades Solidarias Rurales and Guatemala's Mi Familia Progresa were reported to have been implemented successfully alongside investments in the infrastructure and human resources of health facilities [19, 20], and similar supply-side investments have been important in India [38, 60] and Nigeria [78]. Another approach that has been advocated is to link provider payments to uptake of services [77, 87, 94, 107]. For programmes using government facilities (including if they are used for onward referrals), it is important that government facilities receive any linked payments and are able to invest them in infrastructure and human resources $[93,101,105]$

\section{Contracting private providers}

For programmes that are designed to include the opt-in of private providers, there is a risk that programmes will struggle to maintain sufficient number of participating providers if revenue from service users is considered to be inadequate [90, 91, 93, 101]. Providers and programme managers have reported that attempts to contract private providers to implement Janani Suraksha Yojana in some Indian states struggled due to low provider payments [42] and lack of interested providers that meet accreditation criteria [68].

Four particular issues have been documented for the contracting of private providers in voucher programmes. 
Firstly, providers may deliver differential treatment to voucher users compared to fee-paying pregnant women [93, 98]. Secondly, providers may seek to increase revenue by charging pregnant women for services that should be provided free according to the DSF scheme guidelines and agreements, including ultrasound scans, medicines and surgical care [88, 91, 92]. Thirdly, some providers may engage in the 'skimming' of voucher users requiring little intervention and referral of those requiring operations to avoid incurring costs [90, 91], or avoid the risk (and associated litigation) of being held responsible for any adverse outcomes [90]. Fourthly, providers may withdraw from a programme $[89,90,93,108]$.

Programme designers could consider how best to reimburse private facilities for childbirth. As noted above, private facilities may be reluctant to perform surgical interventions if reimbursements are the same regardless of level of intervention [90, 91], and programme officials in India suggested that provider contracts should include a clause stating that caesarean sections must be provided to any voucher user who needed one. Conversely, there are fears that differential reimbursement rates may provide an incentive for participating private facilities to perform high rates of caesarean sections, and that close monitoring may be an important deterrent [83].

\section{Administrative processes and procedural considerations}

Requirements for formal documents to be produced in order to prove eligibility should be carefully considered as in some cases the undocumented will be those most in need, including migrants, young and multiparous women $[22,41,50,53,55,58,76,94$, 101]. In Kenya, for instance, young women were effectively excluded from a voucher scheme as the required government identification cards are only issued at 18 years of age [101]. It may be necessary to allow alternative forms of evidence (such as photos or letters signed by community leaders) [46], or to avoid restrictions and requirements for formal documents altogether $[41,46,53]$.

For short-term cash payment programmes, rigid insistence on bureaucratic processes is a barrier to payment claims by women and some women did not travel to a facility for childbirth if they had heard reports other women had been denied money [48, 49]. The distribution of payments was considered to lack transparency $[46,58]$, and respondents reported being repeatedly sent away from facilities to obtain additional documents [41, 76]. Payments have been denied for reasons including because a seven-day claim period had passed, women were more than 12 weeks gestation at the time of registration, an official would not approve payments to women who gave birth before he took his post, a woman had given birth on the way to a facility and a woman was not accompanied by a community-based worker $[41,48,68,76]$.

It is important that payments to users and participating facilities in DSF programmes use streamlined and timely systems. For short-term cash payment programmes, women received payments as late as 12 months after giving birth [46], or not at all [76], and some families reported selling possessions or incurring debts to pay for transport and medicines for childbirth [47]. Service providers have suggested that such payments to women should be made before childbirth [71], however this may not be enough to overcome irregular disbursements of funding to local levels [41, 42, 58, 72].

The distribution of payments to users can be an administrative burden for officials and service providers, who may not fully understand the programme $[58,59]$. Some service providers highlighted a need for more support to cope with paperwork [59,67], while others had restricted payments to a specific desk at a certain time of day to cope with demand for payments [59]. Local officials suggested that community health workers who manage accounts and distribute payments should be trained accordingly $[68,69]$.

Payments to health facilities have reportedly been delayed due to bureaucratic procedures and a lack of understanding among facility staff regarding what supporting documentation must be submitted [82, 90, 93, 97, 101]. Stringent fraud detection systems may cause delays [106], but need to be balanced against the effects of fraud (see section on corruption). Providers can benefit from feedback mechanisms on how to make payment claims [93]. District officials reacted to unpredictability in funding by adopting first come, first served approaches, sharing smaller amounts among women, borrowing money from other sources, or using their own money [76].

\section{Information systems}

In targeted DSF programmes, information on target groups can help to inform locally appropriate poverty screening tools but may be difficult to obtain or use $[94,95,98,99,101,106]$. Use of existing government systems for monitoring helps to reduce duplication $[81,82,84]$, however these need to be functional district officials in India and Nepal reported not having time, resources or guidelines to conduct monitoring visits [59, 76] and stated that they had to assume quality of care was good unless they heard otherwise [68]. An alternative approach advocated by studies in the review was for communities and nongovernmental organisations to be supported to monitor quality of care, provision of free services and 
distribution of vouchers or cash transfers [45, 70]. Another suggested approach was to contract monitoring to an external organisation, although experiences with Kenya's Vouchers for Health programme indicated that close scrutiny was needed to ensure that the contracted organisation performed monitoring processes as mandated [95, 101]. Such external oversight will also require additional financial outlay and may cause tensions within health services and administrations.

\section{Fraudulent practices and their control}

Fraudulent practices (by users, community-based workers and providers) have been documented as occurring in many DSF programmes. Local government officials may attempt to use programmes to get care for ineligible family members and friends [90], and officials in India and Nepal are reported to have embezzled programme funds $[44,76]$. A recurring complaint across many short-term cash payment and voucher schemes is that families have been exposed to demands for informal payments by staff in health facilities $[39,44,45,47,48$, $50,56,60,63,77,86,93,101]$. In short-term cash payment programmes, staff have been known to deduct money before giving the scheduled payments $[44,46,53$, $59,63]$, and indeed one study in India reported that around half of the amount due to be paid to women through Janani Suraksha Yojana was deducted by service providers [44]. Suggestions from officials include using pre-printed cheques and tracking these using online financial reporting systems $[58,70]$.

Community-based workers have also been known to apply informal charges to women and their families [44, 86, 93, 101]. Commission-based (rather than salaried) payments for such workers may have unintended consequences including workers placing inappropriate pressure on women to travel to health centres to give birth [53], and issuing vouchers to ineligible women in order to achieve the requisite numbers [93]. Initiatives taken by programme managers in Kenya to reduce dishonest behaviour included putting up posters with the true cost of vouchers on market days to prevent informal fees, and switching from commission-based to stipendbased payments for voucher distributors [93].

Some studies have emphasised the importance of strong monitoring systems [106, 108]. If false claims are reported sufficient resources need to be allocated so that they can be adequately followed-up [76]. Similarly, it is important to be able to remove providers from a programme if they are found to be engaged in malpractice [106], although in practice this may be difficult in districts where there are few providers or little interest in joining a programme.

\section{Sustainability issues}

The experience with DSF programmes ranges from cash transfers that have been in operation for almost 30 years, to voucher programmes that have only been implemented as short pilot programmes. Thorough planning and political support seem important for the sustainability of DSF programmes and programme designers need to ensure that all organisations involved in the programme have sufficient capacity to perform mandated tasks [59, 78, 81, 95]. Research has emphasised the importance of good communication between the different levels and different organisations [68, 77, 93]. Planning may take several years as appropriate systems and expertise are developed, and this may be an expensive process [24, 78]. Data should be monitored during implementation to adjust programme design as needed [93, 95]. Local government officials, community leaders and community-based workers can play an important role raising awareness of programmes [55, 81, 84, 101], however regular communication is needed as turnover of officials and poor communication between levels may lead to confusion and distribution of misinformation $[79,81,84,106]$.

Policy champions in donor and governmental organisations proved helpful to ensure political and financial support for programmes in Kenya and Uganda [93, 101, 106]. In Kenya the Vouchers for Health programme reportedly received support from national policy-makers because it was seen as a useful model to prepare for a national social health insurance programme [93]. However, programmes may also become subject to specific political interests. In Nepal, the national government reportedly forced programme roll-out before planning was complete and created tensions with state governments [76].

Ministry of Health engagement is often sought in donor-initiated programmes [84, 101], but programmes may become an administrative burden for underresourced departments and facilities [81, 84]. In Kenya, a planned transfer of ownership to the Ministry of Health was repeatedly delayed and eventually required the assistance of a contracted consultancy firm [93].

\section{Discussion}

This analysis has highlighted a series of well-documented challenges for the implementation of DSF schemes in maternal and newborn health. These include issues of programme scope (in terms of programme eligibility, size and timing of payments and voucher entitlements), wider problems in healthcare systems (including inadequate infrastructure and human resources, lack of medicines and problems with corruption) and the population's awareness and perceptions of programmes and health services. A recent systematic 
review concluded that despite evaluations spanning 15 years of implementation, DSF programmes have yet to demonstrate positive impact of programmes on quality of care or maternal and newborn health outcomes [14]. That finding may reflect insufficient attention during programme design and implementation to improving the quality of care being provided and to conditions of access to comprehensive emergency care [113]. Research highlighted in our analysis indicates that the implementation of DSF programmes may reinforce existing healthcare system problems including poor quality of care, demands for informal fees and the systematic exclusion of vulnerable groups. Vouchers for maternity care services are often proposed as a means to improve quality of care however experiences indicate private providers may find reimbursement rates to be unattractive and engage in practices such as providing differential quality of care or 'skimming' programme users who require minimal intervention. Taken together, these findings suggest a need for greater attention to issues of implementation in DSF programmes and to the context in which they are to be introduced. They indicate serious concerns for the use of DSF as a stand-alone interventions in maternal and newborn health in low- and middleincome countries, and raise questions regarding which (if any) maternal and newborn healthcare services are suited to modalities of DSF.

Where DSF programmes have improved care-seeking, the programmes have tended to include (or be accompanied by) additional investment in health facilities or staff, while those without such investment have struggled (see Tables 2 and 3). Other important factors that have enabled DSF programmes to improve care-seeking have included appropriate payment size and timing for short-term cash payments and cash transfer programmes, and an adequate package of entitlements (including transport costs) in voucher schemes. When well-supported and -supervised, community-based workers, leaders and women's groups have been important facilitators for programmes as they have raised awareness of programme details and helped to counter negative perceptions of programmes.

The longest-running DSF programmes included in this review have been cash transfer schemes that were introduced by national or state governments as part of wider social welfare programmes. Programmes since the launch of the Millennium Development Goals have tended to focus more narrowly on specific maternal health services with the aim to improve their coverage on indicators such as skilled attendants at birth or facility births. Most evaluations have shown quantitative improvements in coverage rates [14]. However, many have relied on funding from donors, and some were implemented for only short pilot periods. Studies have highlighted the high start-up costs of DSF programmes [24, 78], and those running in parallel to welfare systems are likely to have continued high overhead costs. Policy-makers need to consider whether DSF programmes that involve cash payments or vouchers are likely to be an optimal use of resources, or whether increased supply-side investment would be equally effective.

\section{Limitations of the review}

The scope of literature included systematic review may have been limited by use of English search terms and English language databases. Findings were incorporated from a range of studies, including some that were of low quality, in order to gain insights for implementation from a wide range of contexts. The most common methodological weaknesses of studies related to the length of time for follow-up after programme initiation (quantitative studies), and failure to address to role of the researcher on data generation and analysis (qualitative studies). By including studies with such weaknesses, there is a risk that findings reported in this review over-emphasise shortterm factors affecting implementation, and that findings are subject to unknown biases based on the value systems and social positioning of researchers.

\section{Conclusions}

After quite widespread implementation and considerable policy enthusiasm in some quarters, evaluations have shed light on the importance of a number of detailed design and implementation issues as outlined above. The synthesis of findings reveals a complex picture of experiences DSF programmes in maternal and newborn health. While they indicate that cash payments and vouchers can be successful in improving service utilisation rates at least in the short term in an array of contexts, there are frequent concerns about inclusion criteria or distribution mechanisms that effectively exclude migrants, young and multiparous women, about staff charging informal fees once at the facilities, and about the struggle to maintain quality of care under greater demand. Unsurprisingly, the programmes that have successfully promoted uptake of specific maternity care services using cash or voucher incentives, such as Nepal's Safe Delivery Incentive Programme and Bangladesh's Maternal Health Voucher Scheme, are those which were carefully designed with adequate scope (in terms of programme eligibility, payment size and timing, or services and goods to which they provide entitlement) to properly address maternal and newborn health aims, were well-supported in communities and/or which operated within effective healthcare systems. 
Table 2 Summary of key findings from quantitative studies on short-term cash payments and cash transfers

\begin{tabular}{lll}
\hline Programme $\quad$ Effect on care-seeking outcomes ${ }^{a}$ & Key findings from synthesis of factors influencing implementation \\
\cline { 2 - 3 } & Enablers
\end{tabular}

Conditional cash transfers

Comunidades Solidarias Rurales, El Salvador

Mi Familia Progresa, Guatemala

Programa de Asignación Familia, Honduras

Muthulakshmi Reddy Maternity Benefit Scheme, India

Program Keluarga Harapan, Indonesia

Oportunidades, Mexico

Plan de Atención Nacional a la Emergencia Social (PANES), Uruguay

Unconditional cash transfers

Child Grant Programme, Zambia

Short-term cash payments

CHIMACA programme, China

Janani Suraksha Yojana, India
Increased antenatal care. No effect on facility births

Increased skilled birth attendance and facility births. No effect on antenatal care and postnatal care

Increased antenatal care. No effect on postnatal care

Associated with use of public facilities for antenatal care and childbirth

Increased antenatal and postnatal care. Mixed picture of positive and no effect on skilled birth attendance. No effect on facility births

Mixed picture of positive and no effect on skilled birth attendance. No effect on antenatal care

Increased antenatal care. No effect on skilled attendance at birth.

No effect on skilled birth attendance or antenatal care

No effect on antenatal care or postnatal care

Increased skilled birth attendance and facility births. Mixed picture of positive, negative and no
-Awareness generation during

monthly meetings [19]

-Concurrent investments in health facility infrastructure and recruitment of health workers

[19]

-Payments made to women

(not their husbands) [19]

-Concurrent investments in health facility infrastructure and recruitment of health workers [20]

-Conditionalities to submit paperwork at health facilities [21]

-Increased total amount of payments [22]

-Awareness generation by community-based workers [24]

-Awareness generation during monthly meetings $[28,29]$

-Conditionalities for antenatal care were not enforced [35]

None stated

None stated

-Awareness generation by community-based workers $[38,39]$
None stated

None stated

-Poor awareness among women of programme conditionalities [21]

-Delays in receipt of money for women [22]

-Overly bureaucratic process for determining eligibility [22] -Eligibility criteria that restrict payments to women for her first or second live birth [22]

-Poor awareness of the programme among target groups [24]

-Delays in receipt of money for women [24]

-Failure to implement verification systems to penalise households that do not meet conditionalities [24]

-Poor availability of midwives [26] -High start-up costs [24]

-Perceived poor behaviour of staff at participating hospitals [33]

Attitudes towards formal maternity care services of family members who do not attend monthly meetings [34]

-Distance to participating facilities [33]

-Cost of travel to health facilities [33]

-Lack of concurrent investment in health facilities [28, 29]

-Conditionalities for antenatal care were not enforced [35]

-Lack of concurrent investment in health facilities [36]

-Payment too small [37] -Overly difficult process for claiming money [37]

-Poor awareness of the programme among target groups [63] 
Table 2 Summary of key findings from quantitative studies on short-term cash payments and cash transfers (Continued)

\begin{tabular}{|c|c|c|c|}
\hline & $\begin{array}{l}\text { effect on antenatal care and } \\
\text { postnatal care }\end{array}$ & $\begin{array}{l}\text {-Round-the-clock opening of } \\
\text { health facilities }[38,60] \\
\text {-Emergency transport } \\
\text { programmes }[62] \\
\text {-Accreditation of remote health } \\
\text { facilities to reduce travel } \\
\text { distances }[55] \\
\text {-Active involvement of state and } \\
\text { district officials [55] } \\
\text {-Detailed implementation plans } \\
\text { [38] }\end{array}$ & $\begin{array}{l}\text {-Distance and lack of transport } \\
\text { to participating facilities [55,60] } \\
\text {-Payments not made until after } \\
\text { childbirth, thereby reducing } \\
\text { incentive for antenatal care } \\
\text { [55, 62] } \\
\text {-Delays in receipt of money for } \\
\text { women [39, 51, 55, 60, 63] } \\
\text {-Demands for additional or } \\
\text { informal payments [39, 60, 63] } \\
\text {-Perceived poor quality of care } \\
\text { at participating facilities [39] } \\
\text {-Overly bureaucratic process for } \\
\text { determining eligibility [55] } \\
\text {-Inappropriate proxy measures } \\
\text { of poverty, such as caste [38] } \\
\text {-Women who travel to another } \\
\text { area to give birth [51] } \\
\text {-Delays in recruitment of } \\
\text { community-based workers [39] } \\
\text {-Poor awareness of the existence } \\
\text { of community-based workers } \\
\text { [63] } \\
\text {-Delays in payments for } \\
\text { community-based workers [55] } \\
\text {-Increased workloads and } \\
\text { reduced quality of care at } \\
\text { participating health facilities } \\
\text { [55, 62, 63] } \\
\text {-Lack of trained midwives [62] } \\
\text {-Existence of a similar } \\
\text { programme - the National } \\
\text { Maternity Benefit Scheme [55] }\end{array}$ \\
\hline $\begin{array}{l}\text { Safe Delivery Incentive } \\
\text { Programme, Nepal }\end{array}$ & $\begin{array}{l}\text { Increased antenatal care. Mixed } \\
\text { picture of positive or no effect } \\
\text { on skilled birth attendance and } \\
\text { facility births }\end{array}$ & $\begin{array}{l}\text {-Awareness generation by } \\
\text { women's groups in communities } \\
\text { [77] } \\
\text {-Lack of geographical barriers in } \\
\text { the study district [77] } \\
\text {-Universal eligibility [77] } \\
\text {-Output-based reimbursements } \\
\text { for providers [77] }\end{array}$ & $\begin{array}{l}\text {-Poor awareness of the } \\
\text { programme among target } \\
\text { groups [77] } \\
\text {-Delays in receipt of money for } \\
\text { women [77] } \\
\text {-Payments not sufficient to cover } \\
\text { treatment costs [77] } \\
\text {-Demands for additional or } \\
\text { informal payments [77] } \\
\text {-Overly difficult process for } \\
\text { claiming money [77] } \\
\text {-Confusion amongst health } \\
\text { workers and officials regarding } \\
\text { eligibility criteria, sharing of } \\
\text { health worker incentives and } \\
\text { payment mechanisms for } \\
\text { women [77] }\end{array}$ \\
\hline SURE-P programme, Nigeria & $\begin{array}{l}\text { No effect on skilled birth } \\
\text { attendance or antenatal care }\end{array}$ & $\begin{array}{l}\text {-Prompt payments to pregnant } \\
\text { women [78] } \\
\text {-Defined roles and contracts for } \\
\text { local banks and for organisations } \\
\text { that will develop information } \\
\text { systems [78] } \\
\text {-Concurrent programmes to } \\
\text { expand availability of maternity } \\
\text { care services [78] }\end{array}$ & $\begin{array}{l}\text {-Increased workload at } \\
\text { participating health facilities [78] } \\
\text {-High start-up costs including } \\
\text { research, advocacy, development } \\
\text { of information systems, } \\
\text { recruitment of workers for data } \\
\text { collection and the logistics and } \\
\text { security of payments to pregnant } \\
\text { women [78] }\end{array}$ \\
\hline
\end{tabular}

${ }^{a}$ See systematic review for further details of effect on care-seeking outcomes [14]

Research is still needed in a number of areas and the opportunity to update our original systematic review has reminded us of the narrow range of issues and indicators included in many evaluations of DSF programmes. Review papers on this topic are at risk of tunnel vision as a result. It is our considered view that after almost 15 years of evaluating DSF schemes there are some questions about the DSF approach which are important but rarely posed. For example, we found no evaluations that attempted to gauge the 
Table 3 Summary of key findings from quantitative studies on vouchers

\begin{tabular}{lll}
\hline Programme & $\begin{array}{l}\text { Effect on care-seeking outcomes } \\
\text { a }\end{array}$ & Key findings from synthesis of factors influencing implementation \\
& Enablers & Barriers \\
\hline Vouchers for maternity care services &
\end{tabular}

Maternal Health Voucher

Scheme, Bangladesh

Pilot vouchers, Bangladesh

Voucher programme, Cambodia

Chiranjeevi Yojana, India

Vouchers for Health, Kenya

Pilot vouchers, Pakistan

Makerere University Voucher

Scheme, Uganda

HealthyBaby vouchers, Uganda
Increased skilled birth attendance, facility births, antenatal care and postnatal care

Increased skilled birth attendance, facility births, antenatal care and postnatal care

Increased skilled birth attendance and postnatal care. No effect on antenatal care.

No effect on skilled birth attendance, antenatal care and postnatal care

Increased skilled birth attendance and facility births. No effect on antenatal care and postnatal care

Increased facility births. Mixed picture of positive and no effect on antenatal and postnatal care

Increased facility births

Increased facility births, antenatal care and postnatal care
-Activities by community workers and local leaders to raise awareness of the programme [81]

-Inclusion of transport costs $[80,81]$

-'Seed' funds for participating facilities to promote investment in services and capacity [81]

-Inclusion of transport and medicine costs [85]

-Awareness generation by voucher distributors [87] -Output-based reimbursements for providers [87]

-Community health workers provided information on the programme [88]

Use of an existing government system ('below poverty line' cards) as a targeting mechanism [88]

-Awareness generation by voucher distributors and previous service users [99] -Locally appropriate tool for targeting pregnant women from low-income households [99] -Output-based reimbursements for providers [94]

-Awareness generation by voucher distributors [103, 104]

-Inclusion of transport costs [107] -Output-based reimbursements for providers [107]

-Locally appropriate tool for targeting pregnant women from low-income households [106]
-Perceived poor quality of care at participating facilities [81] -Pressure from local politicians to distribute vouchers to ineligible women [81]

Poor awareness of the programme among target groups [85]

-Perceived poor quality of care at participating facilities [85]

None stated

-Poor awareness of the programme among target groups [89]

-Distance to participating facilities in rural areas [88] -Cost of transportation [92] -Demands for additional or informal payments [88, 92] -Providers not reimbursed for postnatal care [88]

-Provider attrition in urban areas [89]

-Waning political commitment [89]

-Perceived poor behaviour of staff at participating hospitals [94]

-Distance and lack of transport to participating facilities [96, 100]

-Cost of travel to health facilities $[99,100]$

- Cost of purchasing vouchers $[96,100]$

-Overly bureaucratic process for determining eligibility [94] -Delays in contract signing and voucher printing [99]

-Many women left the facility within $24 \mathrm{~h}$ after giving birth as there was no one to look after their homes and children [103]

-Distance to participating facilities [104]

None stated

-Turnover of staff in the Ministry of Health [106]

-Cost of travel to health facilities [106]

-Procedural burden of fraud detection system [106] 
Table 3 Summary of key findings from quantitative studies on vouchers (Continued)

-Inclusion (based on geographical needs) of facilities that did not meet minimum quality requirements [106]

Vouchers for merit goods

Tanzanian National Voucher Scheme
Increased use of insecticide-treated nets
-Awareness generation by service providers [109]
-Distribution of vouchers during antenatal care visits misses women who do not seek formal antenatal care [109]

-Cost of purchasing

insecticide-treated net

(even at a reduced rate) [109]

${ }^{a}$ See systematic review for further details of effect on care-seeking outcomes [14]

experience of coercion when birth in a health facility becomes a conditionality for women to receive state welfare payments. There is comparatively little evidence on the implementation of unconditional cash transfers as part of maternal and neonatal health programmes, despite growing interest in these within the international development community. Similarly, comparative research on alternative forms of financing, such as health equity funds, would provide useful insights. Furthermore, research on policy processes and the reasons for introducing DSF schemes rather than efforts to remove user fees or improve supply-side quality of care could also help to generate understanding of the role of these initiatives, how they become sustainable and where they fit (or do not fit) with plans to achieve equitable universal health coverage.

\section{Abbreviations}

ASHA: Accredited social health activists; DSF: Demand-side financing; EPHPP: Effective Public Health Practice Project; GIZ: German Agency for International Cooperation; HIV: Human immunodeficiency virus; PANES: Plan de Atención Nacional a la Emergencia Social; SURE: Supporting the Use of Research Evidence framework; USD: US dollars

\section{Acknowledgements}

We thank Helen Smith (Liverpool School of Tropical Medicine) and Anayda Portela (World Health Organization) for coordinating this series and for their feedback on this article. The linked systematic review was an update of an earlier review that was commissioned and funded by the Australian Agency for International Development and assisted by the Joanna Briggs Institute. We thank Debra Bick (King's College London), Ramila Bisht (Jawaharlal Nehru University) and Tim Ensor (University of Leeds) for their extensive work on that earlier review.

\section{Funding}

This article and the linked systematic review were funded by the World Health Organization's Department of Maternal, Newborn, Child and Adolescent Health as part of a series of reviews on health promotion interventions.

\section{Availability of data and materials}

Data sharing is not applicable to this article because no datasets were generated or analysed during the current study

\section{Authors' contributions}

Both authors contributed equally to the study design and data analysis. BMH prepared the first draft and revised subsequent versions, and SFM contributed to the writing of all drafts. Both authors gave final approval for the paper to be published, and are accountable for all aspects of the work.

\section{Ethics approval and consent to participate}

Ethics approval and consent to participate are not applicable to this article because this is a secondary analysis of existing data that are available in published studies that are listed in the references section.

\section{Consent for publication \\ Not applicable}

\section{Competing interests}

The authors declare that they have no competing interests.

\section{Publisher's Note}

Springer Nature remains neutral with regard to jurisdictional claims in published maps and institutional affiliations.

Received: 24 November 2015 Accepted: 4 August 2017

Published online: 31 August 2017

\section{References}

1. Bohren MA, Hunter EC, Munthe-Kaas HM, Souza JP, Vogel JP, Gulmezoglu AM. Facilitators and barriers to facility-based delivery in low- and middle-income countries: a qualitative evidence synthesis. Reprod Health. 2014;11:71.

2. Thaddeus S, Maine D. Too far to walk: maternal mortality in context. Soc Sci Med. 1994:38:1091-110.

3. Borghi J, Ensor T, Somanathan A, Lissner C, Mills A. Mobilising financial resources for maternal health. Lancet. 2006;368:1457-65.

4. Ensor T, Cooper S. Overcoming barriers to health service access: influencing the demand side. Health Policy Plan. 2004;19:69-79.

5. Krishna A. One illness away : why people become poor and how they escape poverty. Oxford: Oxford University Press; 2010.

6. Murray SF, Hunter B, Bisht R, Ensor T, Bick D. Demand-side financing measures to increase maternal health service utilisation and improve health outcomes: a systematic review of evidence from low- and middle-income countries. Joanna Briggs Institute Library of Systematic Reviews. 2012;10:4165-567.

7. Murray SF, Hunter BM, Bisht R, Ensor T, Bick D. Effects of demand-side financing on utilisation, experiences and outcomes of maternity care in low- and middle-income countries: a systematic review. BMC Pregnancy Childbirth. 2014;14:30.

8. Bellows NM, Bellows BW, Warren C. The use of vouchers for reproductive health services in developing countries: systematic review. Tropical Med Int Health. 2011;16:84-96.

9. Glassman A, Duran D, Fleisher L, Singer D, Sturke R, Angeles G, Charles J, Emrey B, Gleason J, Mwebsa W, Saldana K, Yarrow K, Koblinsky M. Impact of conditional cash transfers on maternal and newborn health. J Health Popul Nutr. 2013;31:48-66. 
10. Gopalan SS, Mutasa R, Friedman J, Das A. Health sector demand-side financial incentives in low- and middle-income countries: a systematic review on demand- and supply-side effects. Soc Sci Med. 2014;100:72-83.

11. Lagarde $M$, Haines A, Palmer N. Conditional cash transfers for improving uptake of health interventions in low- and middle-income countries: a systematic review. JAMA. 2007;298:1900-10.

12. Meyer C, Bellows N, Campbell M, Potts M: The Impact of Vouchers on the Use and Quality of Health Goods and Services in Developing Countries: A systematic review 2011; 2011.

13. Brody CM, Bellows N, Campbell M, Potts M. The impact of vouchers on the use and quality of health care in developing countries: a systematic review. Glob Public Health. 2013;8:363-88.

14. Hunter BM, Portela A, Bick D. The effects of cash transfers and vouchers on the use and quality of maternity care services: a systematic review. PLoS One. 2017:12(3):e0173068.

15. Joanna Briggs Institute: JBI SUMARI. 2015.http://joannabriggs.org/sumari. html. Accessed 21 Jan 2015.

16. The SURE Collaboration. SURE Guides for Preparing and Using EvidenceBased Policy Briefs: identifying and addressing barriers to implementing policy options. Geneva: World Health Organization; 2011.

17. Guanais FC. The combined effects of the expansion of primary health care and conditional cash transfers on infant mortality in Brazil, 1998-2010. Am J Public Health. 2013;103:2000-6.

18. Shei A. Brazil's conditional cash transfer program associated with declines in infant mortality rates. Health Aff. 2013;32:1274-81.

19. De Brauw A, Peterman A: Can Conditional Cash Transfers Improve Maternal Health and Birth Outcomes? 2011. Washington D. C.: International Food Policy Research Institute (IFPRI); 2011.

20. Gutierrez JP: Evaluacion Externa de Impacto del Programa de Transferencias Monetarias Condicionadas: Mi Familia Progresa. 2011. Washington D.C.: Banco Interamericano de Desarrollo; 2011.

21. Morris SS, Flores R, Olinto P, Medina JM. Monetary incentives in primary health care and effects on use and coverage of preventive health care interventions in rural Honduras: cluster randomised trial. Lancet. 2004;364:2030-7.

22. Balasubramanian P, Ravindran TKS. Pro-poor maternity benefit schemes and rural women findings from Tamil Nadu. Econ Polit Wkly. 2012;47:19-22.

23. Public Health Resource Network: Towards Universalisation of Maternity Entitlements: An Exploratory Case Study of the Dr. Muthulakshmi Maternity Assistance Scheme, Tamil Nadu. 2010. New Delhi, India: Public Health Resource Network; 2010.

24. Alatas V, Cahyadi N, Ekasari E, Harmoun S, Hidayat B, Janz E, Jellema J, Tuhiman H, Wai-Poi M. Program Keluarga Harapan: main findings from the impact evaluation of Indonesia's pilot household conditional cash transfer program. 2011. New York: World Bank; 2011.

25. Febriany V, Toyamah N, Sodo J, Budiyati S: Qualitative Impact Study for PNPM-Generasi and PKH on the Provision and the Utilization of the Maternal and Child Health Services and Basic Education Services in the Provinces of West Java and East Nusa Tenggara. Jakarta, Indonesia: The SMERU Research Institute; 2011.

26. Triyana M: Do Health Care Providers Respond to Demand-Side Incentives? Evidence from Indonesia 2014. Chicago, IL: University of Chicago; 2014.

27. Barber SL. Mexico's conditional cash transfer programme increases cesarean section rates among the rural poor. Eur J Pub Health. 2010;20:383-8.

28. Barber SL, Gertler PJ. The impact of Mexico's conditional cash transfer programme, Oportunidades, on birthweight. Tropical Med Int Health. 2008;13:1405-14.

29. Barber SL, Gertler PJ. Empowering women to obtain high quality care: evidence from an evaluation of Mexico's conditional cash transfer programme. Health Policy Plan. 2009;24:18-25.

30. Barham T. A healthier start: the effect of conditional cash transfers on neonatal and infant mortality in rural Mexico. J Dev Econ. 2011;94:74-85.

31. Hernandez Prado B, Ramirez D, Moreno H, Laird N. In: Hernandez Prado B, Cuernavaca HAM, editors. Evaluación del impacto de Oportunidades en la mortalidad materna e infantil In Evaluación externa de impacto del Programa Oportunidades 2003. Mexico: Instituto Nacional de Salud Pública; 2004a.

32. Hernandez Prado B, Salomon JEU, Villalobos MDR, Figueroa JL. Impact of Oportunidades on the reproductive health of its beneficiary population. External Evaluation of the Impact of the Human Development Program Oportunidades 2004b. Cuernavaca, Mexico: Instituto Nacional de Salud Publica; 2004b.

33. Sosa-Rubâi SG, Walker D, Servâan E, Bautista-Arredondo S. Learning effect of a conditional cash transfer programme on poor rural women's selection of delivery care in Mexico. Health Policy Plan. 2011;26:496-507.
34. Urquieta J, Angeles G, Mroz T, Lamadrid-Figueroa H, Hernández B. Impact of oportunidades on skilled attendance at delivery in rural areas. Econ Dev Cult Chang. 2009;57:539-58.

35. Amarante V, Manacorda M, Miguel E, Vigorito A: Do Cash Transfers Improve Birth Outcomes? Evidence from Matched Vital Statistics, Social Security and Program Data 2011. Cambridge, MA: National Bureau of Economic Research; 2011.

36. Handa S, Peterman A, Seidenfeld D, Tembo G. Income transfers and maternal health: evidence from a national randomized social cash transfer program in Zambia. Health Econ. 2015;

37. Hemminki E, Long Q, Zhang W-H, Wu Z, Raven J, Tao F, Yan H, Wang Y, Klemetti R, Zhang T, Regushevskaya E, Tang S. Impact of financial and educational interventions on maternity care: results of cluster randomized trials in rural China, CHIMACA. Maternal \& Child Health Journal. 2013:17:208-21.

38. Amudhan S, Mani K, Rai SK, Pandav CS, Krishnan A. Effectiveness of demand and supply side interventions in promoting institutional deliveries-a quasiexperimental trial from rural north India. Int J Epidemiol. 2013;42:769-80.

39. Carvalho N, Thacker N, Gupta SS, Salomon JA. More evidence on the impact of India's conditional cash transfer program, Janani Suraksha Yojana: quasiexperimental evaluation of the effects on childhood immunization and other reproductive and child health outcomes. PLoS One. 2014;9

40. Chaturvedi S, De Costa A, Raven J. Does the Janani Suraksha Yojana cash transfer programme to promote facility births in India ensure skilled birth attendance? A qualitative study of intrapartum care in Madhya Pradesh. Glob Health Action. 2015;8:27427-7.

41. Chaturvedi S, Randive B. In Reaching the Unreached: Rapid Assessment Studies of Health Programmes Implementation in India. In: Hagopian A, House P, Das A, editors. Are arrangements for public private partnerships for emergency obstetric care services adequate under JSY? A study in Ahmednagar District, Maharashtra. New Delhi: Nidhi Books; 2009.

42. Chaturvedi S, Randive B. Public private partnerships for emergency obstetric care: lessons from Maharashtra. Indian J Community Med. 2011;36:21-6.

43. Chaturvedi S, Upadhyay S, De Costa A, Raven J. Implementation of the partograph in India's JSY cash transfer programme for facility births: a mixed methods study in Madhya Pradesh province. BMJ Open. 2015;5:e006211-1.

44. Coffey D. Costs and consequences of a cash transfer for hospital births in a rural district of Uttar Pradesh, India. Soc Sci Med. 2014;114:89-96.

45. Dasgupta J. Experiences with Janani Suraksha Yojana in Uttar Pradesh: analysis of case studies by SAHAYOG and partners Reviewing Two Years of NRHM 2007. Centre for Health and Social Justice: New Delhi; 2007.

46. Devadasan N, Elias MA, John D, Grahacharya S, Ralte L. A conditional cash assistance programme for promoting institutional deliveries among the poor in India: process evaluation results. Health Services Organisation \& Policy. 2008;24:257-73.

47. Gopalan SS, Durairaj V. Addressing maternal healthcare through demand side financial incentives: experience of Janani Suraksha Yojana program in India. BMC Health Serv Res. 2012;12:319-9.

48. Gupta A. Study of maternal health Care Services for the Rural Poor in Bihar Reviewing Two Years of NRHM 2007. New Delhi: Centre for Health and Social Justice; 2007.

49. Hangmi PZM, Kuki J. In Reaching the Unreached: Rapid Assessment Studies of Health Programmes Implementation in India. In: Hagopian A, House P, Das A, editors. Role of JSY in institutional delivery. A study in Churachandpur District, Manipur. New Delhi: Nidhi Books; 2009.

50. Human Rights Watch. No tally of the anguish: accountability in maternal health care in India. New York: Human Rights Watch; 2009.

51. Joshi S, Sivaram A. Does it pay to deliver? An evaluation of India's safe motherhood program. World Dev. 2014;64:434-47.

52. Khan ME, Hazra A, Bhatnagar I. Impact of Janani Suraksha Yojana on selected family health behaviours in rural Uttar Pradesh. J Fam Welf. 2010;56

53. Krishna A, Ananthpur K. Reasons for seeking (and not seeking) institutional health care: a qualitative examination in 12 villages of Karnataka. 2011. Durham, NC: Working Paper, Sanford School of Public Policy, Duke University; 2011

54. Kumar D, Manisha Dwivedi A. In Reaching the Unreached: Rapid Assessment Studies of Health Programmes Implementation in India. In: Hagopian A, House P, Das A, editors. Has Janani Suraksha Yojana stimulated institutional delivery? A study in Una district of Himachal Pradesh. New Delhi: Nidhi Books; 2009. 
55. Lim SS, Dandona L, Hoisington JA, James SL, Hogan MC, Gakidou E. India's Janani Suraksha Yojana, a conditional cash transfer programme to increase births in health facilities: an impact evaluation. Lancet. 2010;375:2009-23.

56. Lodh A, Haque M, Singh P, Singh Dipu D, Kumar S, Bhatia GP. In Reaching the Unreached: Rapid Assessment Studies of Health Programmes Implementation in India. In: Hagopian A, House P, Das A, editors. To what extent are ASHAs able to perform their assigned roles? A study of Muzaffarpur District in Bihar. New Delhi: Nidhi Books; 2009.

57. Mazumdar S, Powell-Jackson T, Mills A. Financial incentives in health: new evidence from India's Janani Suraksha Yojana. 2012. London: Working paper, London School of Hygiene \& Tropical Medicine; 2012.

58. Nandan D, Malini S, Tripathy RM, Khatter P, Nair KS, Tekhre YL, Dhar N. A rapid appraisal on functioning of Janani Suraksha Yojana in South Orissa. 2008. New Delhi: National Institute of Health and Family Welfare; 2008

59. Nandan D, Mohapatra B, Datta U, Gupta S, Tiwari VK, Nair KS, Adhish V. An assessment of functioning and impact of Janani Suraksha Yojana in Orissa. 2008. National Institute of Health and Family Welfare: New Delhi; 2008.

60. Purohit N, Mehra V, Govil D. Tracking benefits of Janani Suraksha Yojana-a maternal cash transfer scheme: evidence from Rajasthan, India. J Health Manag. 2014;16:289-302

61. Rai SK, Dasgupta R, Das MK, Singh S, Devi R, Arora NK. Determinants of utilization of services under MMJSSA scheme in Jharkhand 'Client Perspective': a qualitative study in a low performing state of India. Indian J Public Health. 2012;55:254-9.

62. Randive B, Diwan V, De Costa A. India's conditional cash transfer Programme (the JSY) to promote institutional birth: is there an association between institutional birth proportion and maternal mortality? PLoS One. 2013:8:e67452-2.

63. Santhya KG, Jejeeboy SJ, Acharya R, Francis Zavier AJ. Effects of the Janani Suraksha Yojana on maternal and newborn care practices: women's experiences in Rajasthan. 2011. Population Council: New Delhi; 2011

64. Santhya KG, Jejeeboy SJ, Francis Zavier AJ. Implementing the Janani Suraksha Yojana: perspectives and experiences of accredited social health activists in Rajasthan. 2011b. Population Council: New Delhi; 2011 b.

65. Singh S, Chaturvedi R. Meeting the health needs of the poor: social audit in Uttar Pradesh. Reviewing Two Years of NRHM 2007. New Delhi: Centre for Health and Social Justice; 2007.

66. Sri BS, NS Khanna R. An investigation of maternal deaths following public protests in a tribal district of Madhya Pradesh, central India. Reproductive Health Matters. 2012;20:11-20.

67. Uttekar BP, Barge S, Deshpande Y, Uttekar V, Sharma J, Shahane S. Assessment of Janani Suraksha Yojana in Himanchal Pradesh. Vadodara, Gujarat: Centre for Operations Research \& Training; 2007a.

68. Uttekar BP, Barge S, Khan W, Deshpande Y, Uttekar V, Sharma J, Chakrawar B, Shahane S. Assessment of ASHA and Janani Suraksha Yojana in Rajasthan. Vadodara, Gujarat: Centre for Operations Research \& Training; 2007d.

69. Uttekar BP, Kumar N, Uttekar V, Sharma J, Shahane S: Assessment of Janan Suraksha Yojana in Assam. 2007e. Vadodara, Gujarat: Centre for Operations Research \& Training; 2007e.

70. Uttekar BP, Kumar N, Uttekar V, Sharma J, Shahane S. Assessment of Janani avam Bal Suraksha Yojana in Bihar. Vadodara, Gujarat: Centre for Operations Research \& Training; 2008b.

71. Uttekar BP, Uttekar V, Chakrawar B, Sharma J, Shahane S. Assessment of Janani Suraksha Yojana in West Bengal. Vadodara, Gujarat: Centre for Operations Research \& Training; 2007b.

72. Uttekar BP, Uttekar V, Chakrawar BB, Sharma J, Shahane S. Assessment of ASHA and Janani Suraksha Yojana in Orissa. Vadodara, Gujarat: Centre for Operations Research \& Training; 2007C.

73. Uttekar BP, Uttekar V, Chakrawar BB, Sharma J, Shahane S. Assessment of Janani Suraksha Yojana in Uttar Pradesh. Vadodara, Gujarat: Centre for Operations Research \& Training; 2008a.

74. Vora KS: Implementation of Janani Suraksha Yojana and other maternal health policies in two Indian states: predictors of maternal health service utilization among poor rural women. 2012.

75. Powell-Jackson T, Hanson K. Financial incentives for maternal health: impact of a national programme in Nepal. J Health Econ. 2012;31:271-84.

76. Powell-Jackson T, Morrison J, Tiwari S, Neupane BD, Costello AM. The experiences of districts in implementing a national incentive programme to promote safe delivery in Nepal. BMC Health Serv Res. 2009;9:97.

77. Powell-Jackson T, Neupane BD, Tiwari S, Tumbahangphe K, Manandhar D, Costello AM. The impact of Nepal's national incentive programme to promote safe delivery in the district of Makwanpur. Adv Health Econ Health Serv Res. 2009;21:221-49.

78. Okoli U, Morris L, Oshin A, Pate MA, Aigbe C, Muhammad A. Conditional cash transfer schemes in Nigeria: potential gains for maternal and child health service uptake in a national pilot programme. BMC Pregnancy And Childbirth. 2014;14:408-8.

79. Ahmed S, Khan MM. A maternal health voucher scheme: what have we learned from the demand-side financing scheme in Bangladesh? Health Policy Plan. 2011;26:25-32

80. Ahmed S, Khan MM. Is demand-side financing equity enhancing? Lessons from a maternal health voucher scheme in Bangladesh. Soc Sci Med. 2011;72:1704-10.

81. Hatt L, Nguyen H, Sloan N, Miner S, Magvanjav O, Sharma A, Chowdhury J, Chowdhury R, Paul D, Islam M, Wang H. Economic Evaluation of DemandSide Financing (DSF) for Maternal Health in Bangladesh. In: Review, Analysis and Assessment of Issues Related to Health Care Financing and Health Economics in Bangladesh 2010. Bethesda, MD: Abt Associates; 2010.

82. Koehlmoos TLP, Ashraf A, Kabir H, Islam Z, Gazi R, Saha NC, Khyang J: Rapid Assessment of Demand-side Financing Experiences in Bangladesh. 2008. Dhaka: International Centre for Diarrhoeal Disease Research, Bangladesh (ICDDR,B); 2008

83. Nguyen H, Hatt L, Islam M, Sloan N, Chowdhury J, Schmidt J-O, Hossain A Wang $H$. Encouraging maternal health service utilization: an evaluation of the Bangladesh voucher program. Soc Sci Med. 2012;74:989-96.

84. Reproductive Health Vouchers Evaluation Team. The reproductive health vouchers program in Bangladesh. Summary of findings from baseline evaluation survey, Working draft. Population Council. 2011;2011

85. Rob U, Rahman M, Bellows B. Using vouchers to increase access to materna healthcare in Bangladesh. Int Q Community Health Educ. 2009;30:293-309.

86. Ir P, Horemans D, Souk N, Van Damme W. Using targeted vouchers and health equity funds to improve access to skilled birth attendants for poor women: a case study in three rural health districts in Cambodia. BMC Pregnancy Childbirth. 2010;10

87. Van de Poel E, Flores G, Ir P, O'Donnell O, van Doorslaer E. Can vouchers deliver? An evaluation of subsidies for maternal health care in Cambodia. Bull World Health Organ. 2014;92:331-9.

88. Bhat R, Mavalankar DV, Singh PV, Singh N. Maternal healthcare financing: Gujarat's Chiranjeevi scheme and its beneficiaries. J Health Popul Nutr. 2009;27:249-58.

89. De Costa A, Vora KS, Ryan K, Sankara Raman P, Santacatterina M, Mavalankar D. The state-led large scale public private partnership 'Chiranjeevi Program' to increase access to institutional delivery among poor women in Gujarat, India: how has it done? What can we learn? PLoS One. 2014;9:e95704.

90. Ganguly P, Jehan K, de Costa A, Mavalankar D, Smith H. Considerations of private sector obstetricians on participation in the state led "Chiranjeevi Yojana" scheme to promote institutional delivery in Gujarat. India: a qualitative study BMC Pregnancy Childbirth. 2014;14:352.

91. Jega FM. Contracting out to improve maternal health: evaluating the quality of care under the Chiranjeevi Yojana in Gujarat, India. International Health Group: University of Liverpool; 2007.

92. Mohanan M, Bauhoff S, La Forgia G, Babiarz KS, Singh K, Miller G. Effect of Chiranjeevi Yojana on institutional deliveries and neonatal and maternal outcomes in Gujarat, India: a difference-in-differences analysis. Bull World Health Organ. 2014;92:187-94.

93. Abuya T, Njuki R, Warren CE, Okal J, Obare F, Kanya L, Askew I, Bellows B. A policy analysis of the implementation of a reproductive health vouchers program in Kenya. BMC Public Health. 2012;12:540.

94. Amendah DD, Mutua MK, Kyobutungi C, Buliva E, Bellows B. Reproductive health voucher program and facility based delivery in informal settlements in Nairobi: a longitudinal analysis. PLoS One. 2013;8:e80582-2.

95. Arur A, Gitonga N, O'Hanlon B, Kundu F, Senkaali M, Ssemujji R: Insights from innovations: lessons from designing and implementing family planning/reproductive health voucher programs in Kenya and Uganda. 2009: Abt Associates Inc:; 2009.

96. Bellows B, Kyobutungi C, Mutua MK, Warren C, Ezeh A. Increase in facilitybased deliveries associated with a maternal health voucher programme in informal settlements in Nairobi. Health Policy Plan: Kenya; 2012.

97. Njuki R, Abuya T, Kimani J, Kanya L, Korongo A, Mukanya C, Bracke P, Bellows B, Warren CE. Does a voucher program improve reproductive health service delivery and access in Kenya? Health policies, systems and management. BMC Health Serv Res. 2015;15 
98. Njuki R, Obare F, Warren C, Abuya T, Okal J, Mukuna W, Kanya L, Askew I, Bracke P, Bellows B. Community experiences and perceptions of reproductive health vouchers in Kenya. BMC Public Health. 2013;13:660.

99. Obare F, Warren C, Abuya T, Askew I, Bellows B. Assessing the populationlevel impact of vouchers on access to health facility delivery for women in Kenya. Soc Sci Med. 2014;102:183-9.

100. Obare F, Warren C, Njuki R, Abuya T, Sunday J, Askew I, Bellows B. Community-level impact of the reproductive health vouchers programme on service utilization in Kenya. Health Policy Plan. 2012;

101. Reproductive Health Vouchers Evaluation Team. The reproductive health vouchers program in Kenya. Summary of findings from program evaluation. Population Council. 2011:2011.

102. Watt C, Abuya T, Warren CE, Obare F, Kanya L, Bellows B. Can reproductive health voucher programs improve quality of postnatal care? A quasiexperimental evaluation of Kenya's safe motherhood voucher scheme. PLoS One. 2015;10:e0122828-8.

103. Agha S. Changes in the proportion of facility-based deliveries and related maternal health services among the poor in rural Jhang, Pakistan: results from a demand-side financing intervention. Int J Equity Health. 2011a;10

104. Agha S. Impact of a maternal health voucher scheme on institutional delivery among low income women in Pakistan. Reprod Health. 2011b;8

105. Okal J, Kanya L, Obare F, Njuki R, Abuya T, Bange T, Warren C, Askew I, Bellows B. An assessment of opportunities and challenges for public sector involvement in the maternal health voucher program in Uganda. Health Res Policy Syst. 2013;11:38.

106. Reproductive Health Vouchers Evaluation Team. The reproductive health vouchers program in Uganda. Summary of findings from program evaluation. Population Council. 2012:2012.

107. Alfonso YN, Bishai D, Bua J, Mutebi A, Mayora C, Ekirapa-Kiracho E. Costeffectiveness analysis of a voucher scheme combined with obstetrical quality improvements: quasi experimental results from Uganda. Health Policy Plan. 2015;

108. Pariyo GW, Mayora C, Okui O, Ssengooba F, Peters DH, Serwadda D, Lucas H, Bloom G, Rahman MH, Ekirapa-Kiracho E. Exploring new health markets: experiences from informal providers of transport for maternal health services in eastern Uganda. BMC Int Health Hum Rights. 2011;11:S10.

109. Hanson K, Marchant $T$, Nathan R, Mponda H, Jones C, Bruce J, Mshinda H, Schellenberg JA. Household ownership and use of insecticide treated nets among target groups after implementation of a National Voucher Programme in the United Republic of Tanzania: plausibility study using three annual cross-sectional household surveys. BMJ. 2009;339:93-6.

110. Koenker HM, Yukich JO, Mkindi A, Mandike R, Brown N, Kilian A, Lengeler C. Analysing and recommending options for maintaining universal coverage with long-lasting insecticidal nets: the case of Tanzania in 2011. Malar J. 2013;12:150-0

111. Mubyazi GM, Bloch P, Magnussen P, Olsen OE, Byskov J, Hansen KS, Bygbjerg IC. Women's experiences and views about costs of seeking malaria chemoprevention and other antenatal services: a qualitative study from two districts in rural Tanzania. Malaria J. 2010;9

112. Jain N, Srivastava NK, Khan AM, Dhar N, Adhish V, Menon S, Nandan D. Assessment of functioning of ASHA under NRHM in Uttar Pradesh. Health and Population: Perspectives and Issues. 2008;31:132-40.

113. Souza JP, Gülmezoglu AM, Vogel J, Carroli G, Lumbiganon P, Qureshi Z, Costa MJ, Fawole B, Mugerwa Y, Nafiou I, Neves I, Wolomby-Molondo J-J, Bang HT, Cheang K, Chuyun K, Jayaratne K, Jayathilaka CA, Mazhar SB, Mor R, Mustafa ML, Pathak LR, Perera D, Rathavy T, Recidoro Z, Roy M, Ruyan P, Shrestha N, Taneepanichsku S, Tien NV, Ganchimeg T, et al. Moving beyond essential interventions for reduction of maternal mortality (the WHO Multicountry Survey on Maternal and Newborn Health): a cross-sectional study. The Lancet. 2013;381:1747-55.

\section{Submit your next manuscript to BioMed Central and we will help you at every step:}

- We accept pre-submission inquiries

- Our selector tool helps you to find the most relevant journal

- We provide round the clock customer support

- Convenient online submission

- Thorough peer review

- Inclusion in PubMed and all major indexing services

- Maximum visibility for your research

Submit your manuscript at www.biomedcentral.com/submit
Biomed Central 